\title{
A centennial catalogue of hydro-geomorphological events and their atmospheric forcing
}

\author{
Pereira S. ${ }^{\text {a,*, }}$, Ramos A.M. ${ }^{b}$, Rebelo L. ${ }^{\text {b }}$, Trigo R.M. ${ }^{\text {b }}$, Zêzere J.L. ${ }^{\text {a }}$ \\ ${ }^{a}$ Centre for Geographical Studies, Institute of Geography and Spatial Planning, Universidade de Lisboa, Rua Branca Edmée Marques, Cidade Universitária, 1600-276 \\ Lisboa, Portugal \\ ${ }^{\mathrm{b}}$ Instituto Dom Luiz (IDL), Faculdade de Ciências da Universidade de Lisboa, Campo Grande Edifício C1, Piso 1, 1749-016 Lisboa, Portugal.
}

\section{A R T I C L E I N F O}

\section{Keywords:}

DISASTER database

Floods

Landslides

Portugal

Circulation Weather Types

\begin{abstract}
A B S T R A C T
The DISASTER database records 1969 unique hydro-geomorphologic cases (floods and landslides) that generated human damages in Portugal during a 150 year-period (1865-2015. The main purposes of this work are the following: to present a national disaster events catalogue; to analyse the atmospheric conditions and to discuss the role of rainfall as main driving force of the hydro-geomorphological disaster events. The main Circulation Weather Types (CWTs) and the presence of Atmospheric Rivers (ARs) of each day of the disaster events were classified using the 20CR dataset (1865-2014) and the NCEP/NCAR reanalysis (2015). These datasets were used to compute the daily cumulative precipitation and the long term climatological year accumulated precipitation 10th, 50th, 90th and 95th percentile spanning 1865-2015 and the accumulated rainfall conditions after and before each disaster event.

In the central and northern Portugal Disaster events are mainly driven by southwest (SW), west (W), northwest (NW) and Cyclonic (C) Weather Types, whereas the CWTs with a southern and eastern component [east (E), southeast (SE) and south (S)] are the main drivers in the south part of the country. Cyclonic CWT is widely associated with convective systems that can generate flash floods and urban floods often responsible for fatalities and injured people. CWTs with a westerly component can be associated to prolonged wet periods that can induce flood events in the main rivers and landslides in the mountain areas. The methodology used to build this disaster event catalogue can be applicable to other study areas, namely the North Atlantic and the Mediterranean regions, where the flood and landslides extremes are related to the atmospheric circulation.
\end{abstract}

\section{Introduction}

In the last twenty years the majority of disasters worldwide have been caused by floods and other weather-related processes (EMDAT, 2016). According to EM-DAT, 6,457 weather-related disasters and 606,000 linked fatalities were recorded worldwide in the period 1995-2015 (EM-DAT, 2016). The increasing number of hydrogeomorphological disasters (floods and landslides) reflect the increasing frequency and magnitude of flood and landslide events, as a direct consequence of climate change (Guha-Sapir et al., 2014; IPCC, 2012). However, these trends are also related with the increasing exposure of people and assets to disaster risk (Promper et al., 2015).

The development of natural disasters databases is decisive for risk management because it highlights the relationships between the occurrence of dangerous natural phenomena and the existence of exposed and vulnerable population. A large effort has been devoted to the inventory, development and exploitation of databases on natural disasters at the

\footnotetext{
* Corresponding author.

E-mail address: susana-pereira@campus.ul.pt (S. Pereira).
}

global scale, such as the EM-DAT (Guha-Saphir and Vos, 2011; Tschoegl, 2006). In Europe a similar effort has been made regarding the production, exploitation and dissemination of disaster information on historical floods and landslides (Barnolas and Llasat, 2007; Guzzetti and Tonelli, 2004; Zêzere et al., 2014), using documental sources, often not considered by the global EM-DAT dataset.

Information on past floods and landslides that caused human consequences in Portugal has been gathered in the DISASTER database (Zêzere et al., 2014). The DISASTER database records unique hydrogeomorphologic cases (floods and landslides) that generated casualties, injuries, and missing, evacuated or homeless people. These hydrogeomorphologic disaster cases are grouped into a more restrict number of disaster events that share the same trigger mechanism and certain magnitude in time and can have a widespread spatial extension, sometimes affecting several river basins.

The atmospheric forcing at different time scales is the main trigger for the hydro-meteorological disasters occurred in Portugal as shown in previous case studies (Fragoso et al., 2010; Liberato et al., 2013; 
Trigo et al., 2014). The previous analyses of selected individual case studies were conditioned by the available datasets or purpose of the study and were evaluated on a case-by-case approach. Some authors selected extreme events based on socioeconomic impacts (Fragoso et al., 2012; Pereira et al., 2016; Rebelo et al., 2018; Trigo et al., 2016, 2014) whereas others analysed precipitation extremes based on different selected criteria (Fragoso et al., 2015; Liberato et al., 2013). Nevertheless, most of these individual events present very different large-scale atmospheric conditions in their genesis.

Recently, it was shown that extreme precipitation in Western Europe (Lavers and Villarini, 2015) and particularly over Portugal (Pereira et al., 2016; Ramos et al., 2015; Trigo et al., 2014) are often associated with the landfall of Atmospheric Rivers (ARs). ARs are long, narrow, and transient corridors of intense horizontal water vapor transport that are usually associated with a low-level jet stream ahead of the cold front of an extratropical cyclone (Dettinger et al., 2015; Newell et al., 1992; Ralph et al., 2006). Due to the high content of water vapor present in the ARs they can lead to intense precipitation over different continental regions, due to its interaction with topography, or by ascent in the warm conveyor belt (e.g. Lavers and Villarini, 2013; Ramos et al., 2017; Stohl et al., 2008). Also a number of studies have linked flood and/or landslide events with specific Circulation Weather Types (CWTs) in Italy (Messeri et al., 2015), Spain (Gilabert and Llasat, 2017; Valenzuela et al., 2018, 2017), Norway (Devolli et al., 2017) and Europe (Prudhomme and Genevier, 2011). Likewise, the relationship between CWTs and longterm changes in flood frequency was studied for the River Eden in the UK (Pattison and Lane, 2012). Nevertheless, to the best of our knowledge, few studies have related the hydro-geomorphological processes with the meteorological circulation at the national level and for a centennial time scale (e.g. Messeri et al., 2015).

Despite their relevance, the list of hydro-geomorphological disaster events in Portugal has not been characterized in terms of the most likely associated circulation weather types. Thus, Portugal still misses a national disaster events catalogue, including details about events dates and duration, human damages, and a systematic assessment of the role of meteorological synoptic forcing of the hydro-meteorological disasters. This understudied component of the hazard has a paramount importance regarding the improved knowledge of the mechanisms that trigger catastrophic flood and landslide events. Furthermore, this type of information is also beneficial to improve national disaster risk assessment, protection and mitigation.

According to this context, the first main purpose of this work is to present a national disaster events catalogue spanning 1865-2015, including details on disastrous floods and landslides events, such as human damages, spatial distribution of the event, atmospheric circulation, presence of Atmospheric Rivers and antecedent rainfall conditions. The other main purpose of this work is to discuss the driving role of rainfall to generate hydro-geomorphological disaster events. In order to fulfil these main purposes, this work has the following objectives: (1) to characterize the hydro-geomorphological disaster events documented in the DISASTER database; (2) to classify and analyse the main atmospheric circulation characteristics by means of weather types associated with the disaster events, including possible presence of Atmospheric Rivers; (3) to evaluate the daily cumulative precipitation and the long term climatological year accumulated precipitation after and before each disaster event; (4) to present a national disaster events catalogue and to discuss the role of rainfall as main driving force of hydro-geomorphological disasters in Portugal.

This study is part of the project FORLAND - Disastrous floods and landslides in Portugal: driving forces and applications for land use planning; http://www.ceg.ulisboa.pt/forland/en). The driving forces of hydro-geomorphologic disasters are multiple and may contribute in a distinct way to generate disaster risk at the local level. Data exploitation at the regional and local levels indicates that disaster patterns can be related with factors other than climate (Pereira et al., 2016; Santos et al., 2014), like the predisposing factors of flood and landslide suscep- tibility (e.g. elevation, geology, soil types) (Santos et al., 2018; Zêzere et al., 2018), the land use change (Tavares et al., 2012) and the evolution of social vulnerability to hydro-geomorphologic hazards (GuillardGonçalves et al., 2014). This study focuses only on the climatic and atmospheric forcing of the disasters events.

\section{Data and methods}

\subsection{DISASTER database and disaster events}

In a previous work, the DISASTER database was presented (Zêzere et al., 2014) and past floods and landslides that caused human consequences in Portugal were summarized for the period 1865-2010. This database registers those floods and landslides that, independently of the number of affected people, caused casualties, injuries, evacuated or homeless people (Zêzere et al., 2014). In the current work, the DISASTER database was updated for the period 2011-2015 using the same data collection methodology applied in the DISASTER project (Zêzere et al., 2014). The data collection was based on the analysis of daily and weekly newspapers published since 1865 at the national and regional levels in order to guarantee the best spatial coverage of the country. The same authors defined a disaster case as a unique hydrogeomorphologic occurrence (flood or landslide), which fulfils the DISASTER database criteria and is related to a unique spatial location and a specific period of time (Zêzere et al., 2014). The DISASTER database provides detailed information about each disaster case, such as its type (flood or landslide), date of occurrence, publishing date of the newspapers, location ( $\mathrm{x}$ and $\mathrm{y}$ coordinates), and number of human damages (casualties, injured, missing, evacuated and displaced people). Spatial distribution of disaster flood and landslide cases is showed in Fig. 1. The DISASTER database includes 1969 hydro-geomorphological cases for the period 1865-2015, of which $85 \%$ correspond to flood cases (Fig. 1a) and the remaining to landslide cases (Fig. 1b) that caused human damages.

In this work, the disaster cases are grouped into a set of discrete disaster events that share the same trigger mechanism and a specific magnitude in time. Disaster events were selected respecting the following criteria: (i) the disaster event should include at least 3 disaster cases; (ii) in temporal terms a disaster event ends when 3 consecutive days without recorded disaster cases are found; and (iii) in spatial terms disaster events must be located within a relatively continuous spatial pattern devoid of isolated disaster cases. According to these criteria, a total of 130 disaster events were identified and characterized for the period 1865-2015 (see Table A in Appendix).

All disaster events were characterized taking into account the following attributes: Event ID; hydro-geomorphologic event type (e.g. landslides [L], floods [F], flash floods [FF], urban floods [UF]); date of beginning/end of the event (year, month and days); affected districts; dominant circulation weather type of the triggering event; presence or absence of Atmospheric Rivers; duration in days; number of disaster cases; number of fatalities, injured, evacuated, displaced people and total affected people.

The distribution of disaster events, number of disaster cases, duration in days, fatalities, and injured, evacuated and displaced people were analysed with the EasyFit-Mathwave software (http://www.mathwave.com/en/home.html) in order to test the probability distribution that best fits to data. The Kolmogorov Smirnov (K-S) test was applied to obtain the best fit probability distribution. Fig. 2.

\subsection{Reanalysis dataset}

In order to analyse the meteorological conditions in a comprehensive way, a long-term reanalysis was used. In this case, we have used the 20th Century Reanalysis (20CR) version 2c (Compo et al., 2011) from the National Oceanic and Atmospheric Administration/Earth System Research Laboratory Physical Sciences Division (NOAA/ERSL PSD) 

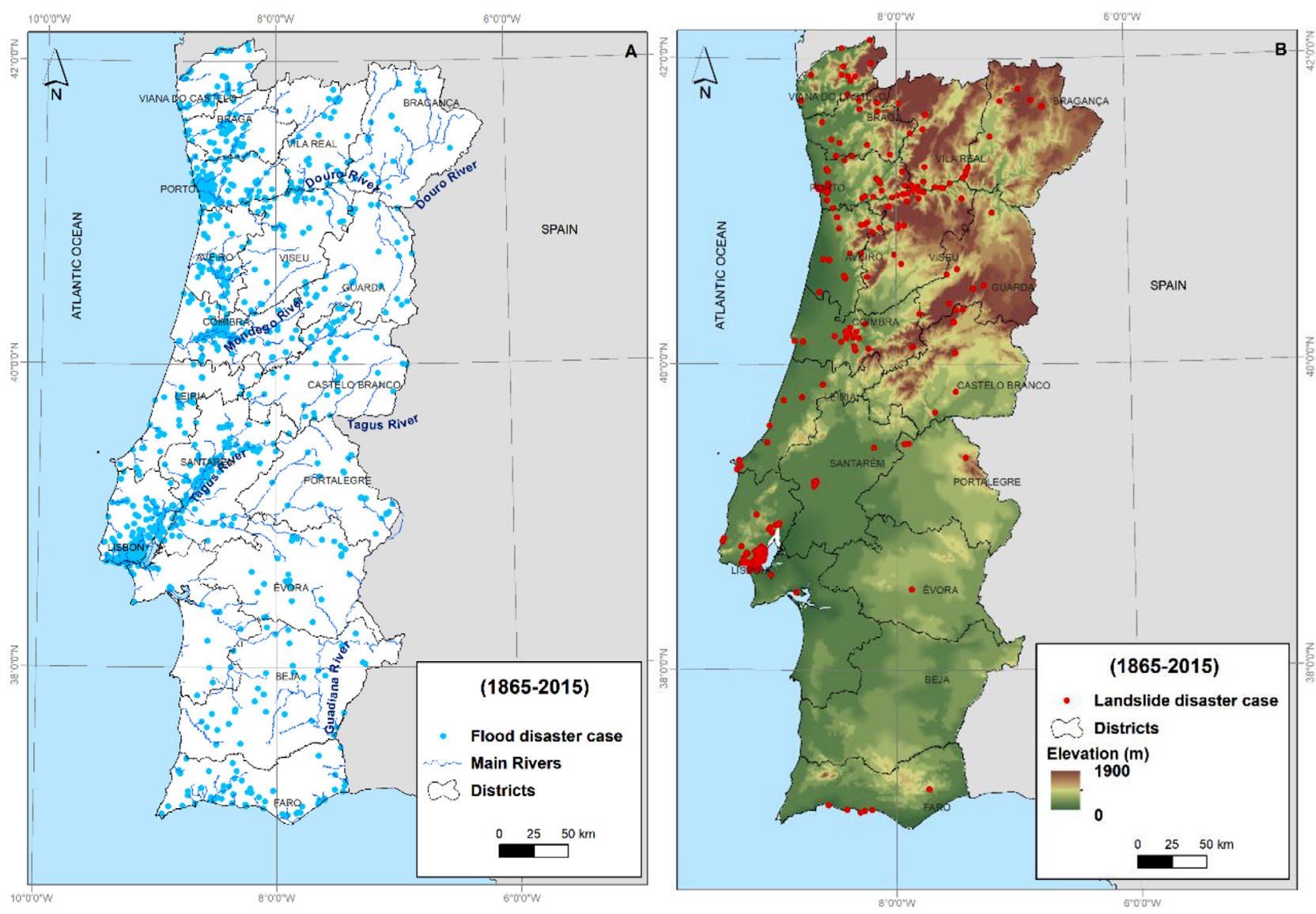

Fig. 1. Flood disaster cases (a) and landslide disaster cases (b) (1865-2015).

with a resolution of $2^{\circ}$ by $2^{\circ}$ latitude longitude grid between 1865 and 2014. This dataset is suitable for this type of analysis because it provides a continuous 3-D description of many meteorological fields from 1851 to 2014 and was already used successfully by the authors in others works (Pereira et al., 2016; Trigo et al., 2014).

The extracted ensembles mean fields correspond to the daily mean sea level pressure field and the 3-hourly precipitation rate at the surface (which were converted into daily-accumulated precipitation). Moreover, the specific humidity (q) and the zonal (u) and meridional (v) wind components at the $1000 \mathrm{hPa}, 925 \mathrm{hPa}, 850 \mathrm{hPa}, 700 \mathrm{hPa}, 600 \mathrm{hPa}$, $500 \mathrm{hPa}, 400 \mathrm{hPa}$ and $300 \mathrm{hPa}$ pressure levels were also extracted.

In addition, we have used the NCEP/NCAR (Kalnay et al., 1996) reanalysis at a $2.5^{\circ}$ resolution in order to have available data for the year 2015 where a disaster event occurred (\#130 in Table A in Appendix). Therefore we have download the same variables as the ones mentioned above for the 20CR and interpolated the NCEP/NCAR reanalysis to a $2^{\circ}$ resolution in order to apply the exact same methodology as the one applied for the 20CR particularly in Section 2.3, Section 2.4 and Section 2.5.

\subsection{Precipitation analysis}

Regarding the precipitation, as mentioned above, we have converted the 3-hourly precipitation rate at surface to daily-accumulated precipitation in order to have an approximation of the precipitation landfall at the Iberia Peninsula (IP) domain. We are aware that the precipitation output from the reanalysis precipitation is not the optimal solution due to its coarser resolution $\left(2^{\circ}\right.$ by $\left.2^{\circ}\right)$. Sun et al. (2018) show that the reanalysis datasets generally had the largest discrepancies when compared with observational datasets like gauge-based and satellite-related. In ad- dition, the coarser resolution of the $20 \mathrm{CR}$ will not represent the extreme values of precipitation in the anomalous precipitation events as shown in Pereira et al. (2016) or Trigo et al. (2014), however it can depict well the anomalous precipitation, even if the precipitation field is smoother than reality. Taking into account the reasons mentioned above we choose the precipitation $20 \mathrm{CR}$ because it provides a consistent precipitation dataset that could be comparable for the entire centennial period (1865-2015).

Secondly, in order to have the daily mean accumulated precipitation over mainland Portugal, we have selected 6 grid points from the 20CR and NCEP/NCAR that are located over Portugal and its average was computed. Therefore, for each day since 1865 till 2015 we have the daily mean accumulated precipitation over mainland which was used in this work. Additionally, the daily cumulative precipitation for Portugal between 1 September and 31 of August was computed for each climatological year, starting in 1 September of 1865-31 of August 1866 and ending in 1 September of 2014-31 of August 2015.

The long-term climatological year accumulated precipitation 10th, 50th, 90th and 95th percentile was also computed for the period 18652015, highlighting the disaster events and the days with Atmospheric Rivers.

In addition, the accumulated precipitation percentile of the first day and the last day of the disaster event, and the increase in the accumulated precipitation percentile during the event were calculated. A hierarchical cluster analysis of the accumulated precipitation percentiles that characterize each disaster event was performed using the Ward method (Ward, 1963) in the clusters union rule in order to identify if the rainfall was the main driving force of the disaster events. In the Ward's method the distance between two clusters, A and B informs on how much the sum of squares will increase when the clusters are merged (Ward, 1963): 


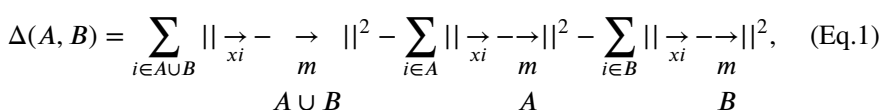$$
=\frac{n_{A} n_{B}}{n_{A+} n_{B}}\|\underset{m}{\rightarrow} \underset{m}{\rightarrow}\|^{2},
$$

$A \quad B$

where $\rightarrow$ is the centre of cluster $j$, and $n_{j}$ is the number of points in it. $\Delta$ $m$

$j$

corresponds to the merging cost of combining clusters $A$ and $B$.

In the hierarchical clustering analysis, the sum of squares starts out at zero (each point is in its own cluster) and then grows as clusters are merged. This method keeps this growth as small as possible. The number of points shows up in $\Delta$, as well their geometric separation. Although, given two pairs of clusters, whose centres are equally distant, the Ward's method will merge the smaller clusters. At the same time, this method is constrained by previous choices as to which clusters to form. In practice this means that the sum-of-squares for a given number of $\mathrm{k}$ clusters is usually larger than the minimum for that $\mathrm{k}$, and larger than what $\mathrm{k}$ means will achieve (Murtagh and Legendre, 2014; Ward, 1963).

This analysis was based on four variables for all the 130 disaster events: the percentile of the first day of the event; the percentile of the last day of the event; the percentile increase during the event; and the number of disaster cases within each disaster event. According to the obtained results with the Ward algorithm, connection tree and agglomeration cost tables, four clusters were identified, in order to reduce the number of clusters until there is a jump in the cost of agglomeration. Euclidian distances (not standardized) were used as metric distances.

\subsection{Circulation weather types}

The weather type classification used is an automated version of the Lamb weather type (Lamb, 1972) procedure initially developed by Jenkinson and Collinson (1977) for the United Kingdom and latter adapted for Portugal (Trigo and DaCamara, 2000), is often named as circulation weather types (CWT). The atmospheric circulation conditions are determined using physical or geometrical parameters associated to the direction, velocity and vorticity of the geostrophic flow based on 16 SLP grid points (Trigo and DaCamara, 2000) retrieved from the 20CR and NCEP/NCAR (see Section 2.2). The daily CWTs were computed with the 16 grid points centred in Portugal, for the 1865-2015 period using the same method as Trigo and DaCamara (2000). (For the sake of brevity and since this is not a methodological paper regarding the WTs please refer to Trigo and DaCamara (2000) for a comprehensive description of the methodology and for the SLP fields associated to each CWT).

Using this methodology, 26 different weather types are defined, where the flow is classified into eight directional CWTs, namely, northeast (NE), east (E), southeast (SE), south (S), southwest (SW), west (W), northwest (NW), north (N), and two rotational CWTs, namely, cyclonic (C) and anticyclonic (A) and 16 hybrid types (8 for each $\mathrm{C}$ or A hybrid). Since it is not practical to work with 26 CWT we have re-ordered them into 10 types where the 16 hybrid ( 8 for each $\mathrm{C}$ or A hybrid) CWT are assigned to their corresponding directional CWT (Ludwig et al., 2016; Rebelo et al., 2018).

Besides the original application to Portugal (Trigo and DaCamara, 2000), a number of studies have analysed the relationship between the different CWT and precipitation (Cortesi et al., 2014, 2013) or temperature (Peña-Angulo et al., 2016) in the Iberian Peninsula. Most of the precipitation in Portugal is produced by just a few CWT that contribute to a large percentage of the monthly precipitation including the Cyclonic (C) and those with an westerly component (SW/W/NW). In addition, the E, SE and S CWT's can also produce some precipitation in Portugal especially in the south since they are usually associated to cut off low systems and convective processes (Ramos et al., 2014a). Finally, the Anticyclonic (A) and northerly types (NE and N) are predominant in summer months and usually associated to dry conditions in mainland Portugal. Taking this into account we went a step further and combined some of the CWT into five groups considering its rainfall properties described above: (1) the C type; (2) SW/W/NW types, (3) E/SE/S types; (4) A type and (5) NE/N types.

\subsection{Atmospheric rivers database}

The AR detection scheme is based on the vertically integrated horizontal water vapour transport (IVT), following the same approach and domain as Ramos et al. (2015). As mentioned before the ARs are regions of enhanced corridors of integrated water vapour (IWV) and IWV transport (IVT) in long $(>2000 \mathrm{~km})$ and narrow $(500-1000 \mathrm{~km})$ corridors (Ralph et al., 2006, 2004; Ralph and Dettinger, 2012; Zhu and Newell, 1998). The use of the IVT allow us to identify regions of intense water vapour transport.

The ARs methodology used here was first developed for the UK by Lavers et al. (2012, 2013) and adopted later by Ramos et al. (2015) for the Iberia Peninsula.

The method allowed us the detection of the ARs at a certain reference meridian. In our case, since we were interested in the ARs that make landfall in the Western Iberian Peninsula we applied the detection scheme at the $10^{\circ} \mathrm{W}$ meridian and between $35^{\circ} \mathrm{N}$ and $45^{\circ} \mathrm{N}$.

The IVT was calculated at a 6-hourly period in the 1865-2015 period, between $1000 \mathrm{hPa}$ and $300 \mathrm{hPa}$, using the $q, u, v$ variables extracted from the 20CR and NCEP/NCAR. The IVT was calculated as follows in an Eulerian framework (e.g. Lavers et al., 2012; Neiman et al., 2008):

$I V T=\sqrt{\left.\left.\left(\frac{1}{g} \int_{1000 h P a}^{300 h P a} q u d p\right)\right)^{2}+\left(\frac{1}{g} \int_{1000 h P a}^{300 h P a} q v d p\right)\right)^{2}}$,

where $q$ is the layer averaged specific humidity, $u$ and $v$ the zonal and meridional layer averaged wind, $d p$ is the pressure difference between two adjacent levels and $g$ is the gravity acceleration.

The latitudinal IVT threshold is computed by extracting the maximum IVT at $1200 \mathrm{UTC}$ each day, between $35^{\circ} \mathrm{N}$ and $45^{\circ} \mathrm{N}$ (for the $10^{\circ} \mathrm{W}$ reference meridian), considering the entire $20 \mathrm{CR}$ period. The 85th percentile IVT threshold was computed as suggested by Lavers et al. (2011) for the UK and acknowledging that Ramos et al. (2015) recently confirmed its suitability for the Iberian Peninsula. Two different thresholds were used, one for the extended winter (October-March) and another one for the extended summer (April-September) in order to be in line with the seasonal IVT climatology. The threshold for the extended winter corresponds to $478 \mathrm{~kg} / \mathrm{m} / \mathrm{s}$ while for the extended summer to $404 \mathrm{~kg} / \mathrm{m} / \mathrm{s}$.

The following methodology was then applied at a 6-hourly time frame:

1 For each 6-hour time step in the reanalysis, the maximum value in IVT was extracted for the grid points located on the $10^{\circ} \mathrm{W}$ reference meridian between $35^{\circ} \mathrm{N}$ and $45^{\circ} \mathrm{N}$. If the obtained value exceeded the correspondent threshold the grid point was highlighted.

2 A western/eastern search was performed to identify the maximum IVT at each longitude, with the location of the grid points that exceeded the correspondent IVT threshold being flagged.

3 However, ARs have to extend for at least $2000 \mathrm{~km}$ (Ralph et al., 2006, 2004; Ralph and Dettinger, 2012; Zhu and Newell, 1998). therefore a minimum length threshold was also imposed. If the values flagged in step 2 exceed the threshold of $2000 \mathrm{~km}$ we classify it as an AR. Taking into account that the length of a degree at $40^{\circ} \mathrm{N}$ is approximately $\sim 85 \mathrm{~km}$ and the resolution of the reanalysis data ( $2^{\circ}$ grid box), it was determined that exceeding 12 contiguous points $\left(12^{*} 2^{\circ}=24^{\circ}\right.$ $* 85 \mathrm{~km} \sim 2000 \mathrm{~km}$ ) would satisfy the length criteria of an AR. This condition data was checked every 6 hours, with it being considered an AR time step when these criteria were fulfilled. 

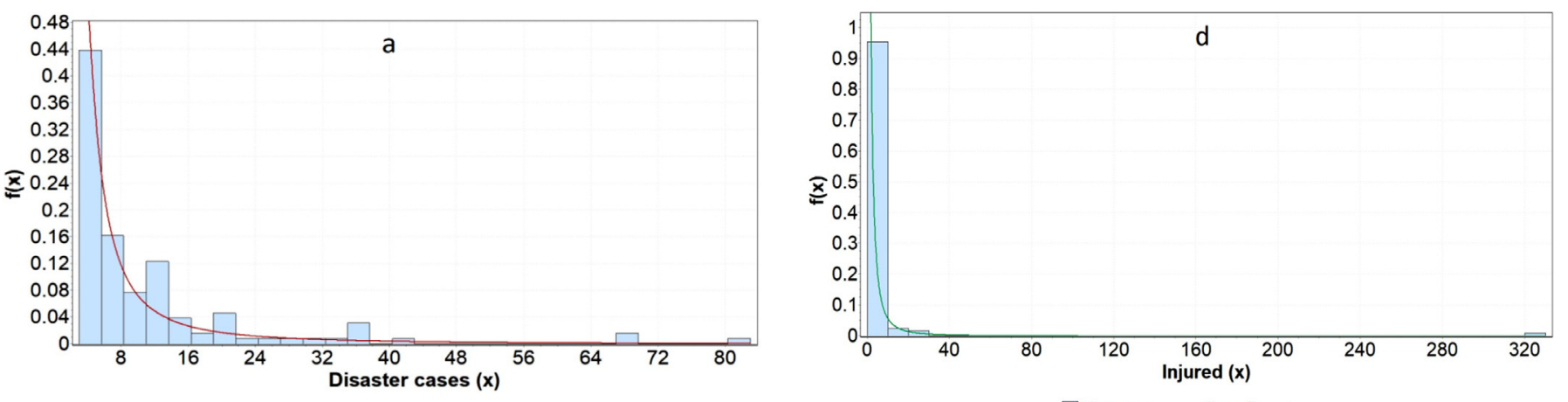

-Pearson $5(3 P)$
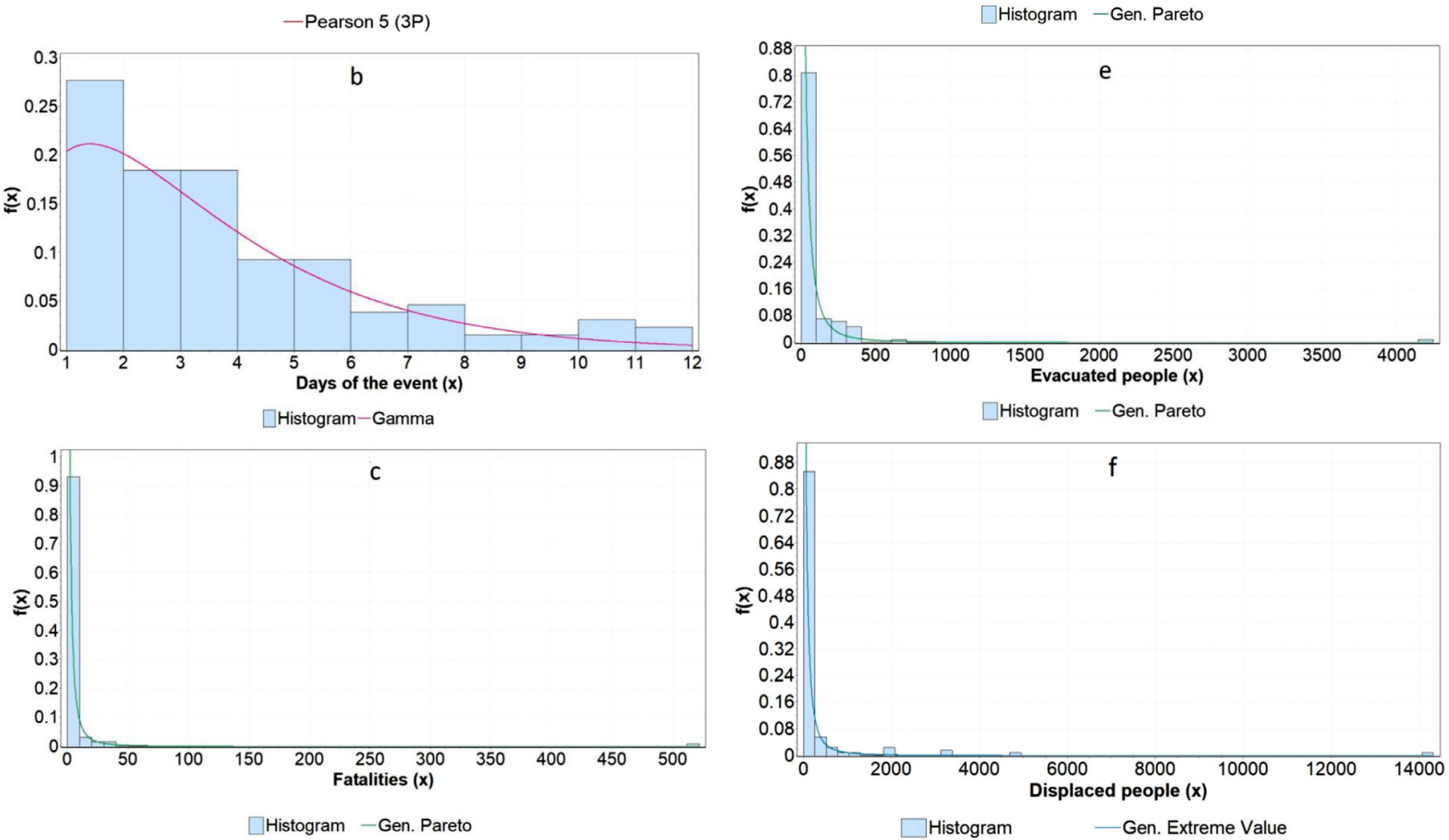

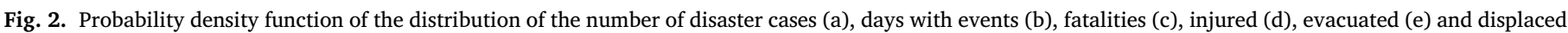
people (f) and the corresponding best fit probability distributions to sample data. Note: graphs have different scales.

Table 1

Number of disaster cases and corresponding disaster events per disaster cases, fatalities, injured, evacuated and displaced people.

\begin{tabular}{llll}
\hline & \multirow{2}{*}{$\begin{array}{l}\text { Disaster cases } \\
\text { total }\end{array}$} & \multicolumn{2}{l}{ Disaster events } \\
\cline { 3 - 4 } & & total & $\%$ of the DISASTER database \\
\hline Disaster cases & 1969 & 1411 & 71.7 \\
Fatalities & 1255 & 938 & 74.7 \\
Injured & 913 & 573 & 62.8 \\
Evacuated & 14,911 & 12,087 & 81.1 \\
Displaced & 423,307 & 40,827 & 96.5
\end{tabular}

\section{Results and discussion}

\subsection{Disaster events characteristics}

The DISASTER database includes 130 disaster events that contain 1411 flood and landslide disaster cases, which corresponds to $71.7 \%$ of the complete DISASTER database (Table 1). Disaster events include $96.5 \%$ of displaced people and $81.1 \%$ evacuated people of the complete
DISASTER database. On contrary, fatalities and injured people are less well represented by disaster events, corresponding to $74.7 \%$ and $62.8 \%$, respectively (Table 1 ) of the total database. In practice this means that fatalities and injured people are also frequently reported in isolated disaster cases, which are not considered as a disaster event, following criteria referred in Section 2.1.

The best fit probability distributions obtained for the number of disaster cases, number of days, number of fatalities and injured, evacuated and displaced people are listed in Table 2 and events with 0.01 and 0.05 probabilities are signed in Table A in Appendix. The number of disaster cases counted in each event is best fitted to a Pearson 5 probability distribution (Fig. 2a). For instance, the probability of a disaster event with $<10$ disaster cases is 0.738 , while $>50$ disaster cases is 0.055 . Disaster event \#8 registered the highest number of disaster cases (83) and was previously studied in detail by Pereira et al. (2016) in terms of atmospheric circulation and flood impacts, especially along the Douro international basin. Disaster events \#8 (20-28 December 1909), \#84 (25-26 November 1967) and \#95 (5-16 February 1979) have a probability $\leq 0.05$ according to the number of disaster cases generated. 
Table 2

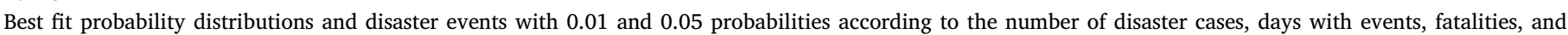
injured, evacuated and displaced people. Disaster events ID are described in supplementary Table A in Appendix.

\begin{tabular}{|c|c|c|c|c|c|c|}
\hline & Min. & Max. & Best fit probability distribution & Kolmogorov Smirnov test & Disaster events ID with $P \leq 0.01$ & Disaster events ID with $P \leq 0.05$ \\
\hline Disaster cases & 3 & 83 & Pearson 5 & 0.1319 & - & $8 ; 84 ; 95$ \\
\hline Days with events & 1 & 12 & Gamma & 0.1454 & $95 ; 101$ & $8 ; 10 ; 11 ; 28 ; 37 ; 47 ; 95 ; 101 ; 111$ \\
\hline Fatalities & 0 & 522 & Generalized Pareto & 0.2397 & 84 & $1 ; 7 ; 8 ; 38 ; 84 ; 97$ \\
\hline Injured & 0 & 330 & Generalized Pareto & 0.3088 & 84 & $10 ; 13 ; 60 ; 82 ; 84 ; 107$ \\
\hline Evacuated people & 0 & 4244 & Generalized Pareto & 0.0615 & 95 & $8 ; 32 ; 95 ; 101 ; 114$ \\
\hline Displaced people & 0 & 14,322 & Generalized Extreme Values & 0.2368 & $73 ; 94 ; 95 ; 97$ & $35 ; 59 ; 73 ; 82 ; 84 ; 88 ; 94 ; 95 ; 97 ; 101$ \\
\hline
\end{tabular}

Table 3

Disaster event types and corresponding human impacts.

\begin{tabular}{|c|c|c|c|c|c|}
\hline Disaster event type & $\%$ of events & $\%$ of fatalities & $\%$ of injured & $\%$ of evacuated people & $\%$ of displaced people \\
\hline Floods & 13.1 & 4.3 & 1.6 & 3.0 & 1.0 \\
\hline Flash floods & 7.7 & 1.1 & 0.0 & 1.9 & 0.8 \\
\hline Urban floods & 6.2 & 0.2 & 0.2 & 5.9 & 1.1 \\
\hline Landslides & 0.8 & 0.0 & 1.2 & 0.0 & 0.0 \\
\hline Floods + flash floods & 5.4 & 6.4 & 1.2 & 4.2 & 0.2 \\
\hline Floods + urban floods & 5.4 & 0.4 & 2.3 & 2.5 & 12.7 \\
\hline Floods + landslides & 19.2 & 7.5 & 9.8 & 8.2 & 5.3 \\
\hline Flash floods + urban floods & 9.2 & 59.3 & 62.0 & 5.1 & 2.6 \\
\hline Urban floods + landslides & 4.6 & 1.6 & 3.3 & 0.5 & 0.2 \\
\hline Floods + flash floods + urban floods & 1.5 & 1.5 & 0.7 & 0.7 & 2.1 \\
\hline Floods + flash floods + landslides & 3.8 & 2.3 & 3.5 & 37.0 & 36.4 \\
\hline Floods + urban floods + landslides & 9.2 & 4.5 & 2.8 & 4.3 & 4.7 \\
\hline Flash floods + urban floods + landslides & 8.5 & 3.0 & 3.8 & 14.7 & 26.9 \\
\hline Floods + flash floods + urban floods + landslides & 5.4 & 8.0 & 7.7 & 12.0 & 6.2 \\
\hline
\end{tabular}

The number of days with events is best fitted to a Gamma probability distribution (Fig. 2b). Disaster events have an average duration of 3.4 days and the probability of events with 1 day is 0.145 , although these events where responsible for $58.8 \%$ of total mortality associated to disaster events. Longer duration events up to 12 days (\#95 and \# 101) have a probability $\leq 0.01$.

Number of fatalities, number of injured and number of evacuated people per event are best fitted to a Generalized Pareto distribution, while the number of displaced people is best fitted to a Generalized Extreme values distribution (Table 2). Concerning the number of fatalities distribution, the event \#84 has a probability of 0.009 . This event was a flash flood that affected several municipalities in the Lisbon Metropolitan Area in 1967, generating $55.7 \%$ of fatalities and $57.6 \%$ of injured people associated to disaster events (Fig. 2c) in the country. This extreme event of mortality was described in detail in previous work by Pereira et al. (2017) and Trigo et al. (2016). The probability of an event to generate more than one fatality or more than one injured person is 0.37 and 0.39 , respectively (Fig. 2c and d).

Event \#95 is the most important extreme disaster event concerning evacuated and displaced people (probability $\leq 0.01$ in both cases) following the general floods occurred in 1979 especially along the Tagus basin (Rebelo et al., 2018). For instance, the probability of an event to generate more than 10 evacuated or displaced persons is 0.66 in both cases (Fig. 2e and f).

Flood and landslide types recorded in disaster events (Table 3) show that single damaging landslide events are very rare, and are usually combined with damaging floods and flash floods because they often require long rainy periods and a higher soil water content (Vaz et al., 2018; Zêzere et al., 2005, 2015). Disaster events with both floods and landslides recorded the highest percentage of events (19.2\% of events), while floods present the second highest percentage (13.1\%). It should be noted that flash flood and urban floods events were responsible for $59.3 \%$ of fatalities and $62 \%$ of injured people recorded in disaster events. The highest percentage of evacuated (37\%) and displaced people $(36.4 \%)$ was associated with disaster events with floods, flash floods and landslides (Table 3).

\subsection{Temporal and spatial distribution of the disaster events}

The annual probability of a disaster event occurrence is 0.62 while the annual probability of 5 or more events per year is 0.01 . The temporal distribution of disaster events (Fig. 3a) shows that there are a few years with a maximum of five disaster events per year (1959, 1960, 1966 and 2001). During the first 70 years of the series (until 1935) the annual average of events was 0.36 and most of years (48) did not register disaster events. These results match with the incompleteness period of the DISASTER database in terms of number of records, as Zêzere et al. (2014) previously showed it. In the period, 1935-1970 it was recorded the highest number of disaster events (30 events) as well as the highest annual average of events (0.86 events). Since 1971, the annual average of disaster events decreased to 0.66 .

The accumulated percentage of fatalities generated by disaster events shows a huge increase associated to the extreme mortality event occurred in November 1967 (\#84,Trigo et al., 2016), whereas the accumulated percentage of displaced people shows a great increase due to the February 1979 event (\#95, Rebelo et al., 2018) (Fig. 3a). In the last 15 years, despite the existence of a similar number of disaster events, the accumulated percentage of fatalities and displaced people shows a remarkable decrease (Fig. 3a).

In Portugal the rain gauge of Lisbon Geophysics has the longest daily rainfall data series in the country since 1864 (Kutiel and Trigo, 2014). Total annual rainfall at Lisbon Geophysics rain gauge was represented on Fig. $3 \mathrm{~b}$ in order to be compared with the temporal distribution of the number of hydro-geomorphological events (Fig. 3a). The average annual rainfall in Lisbon is approximately $700 \mathrm{~mm}$. The highest number of disaster events matches the period from 1935-1970 where annual average rainfall (and extreme events) were more frequent. In general, when the annual average rainfall increased there was a rise in the number of disaster events.

The preliminary exploitation of the DISASTER database highlighted the existence of contrasting disaster patterns among the Portuguese regions (Zêzere et al., 2014). In this work, the percentage of disaster events per district was calculated considering the number of events that af- 
a

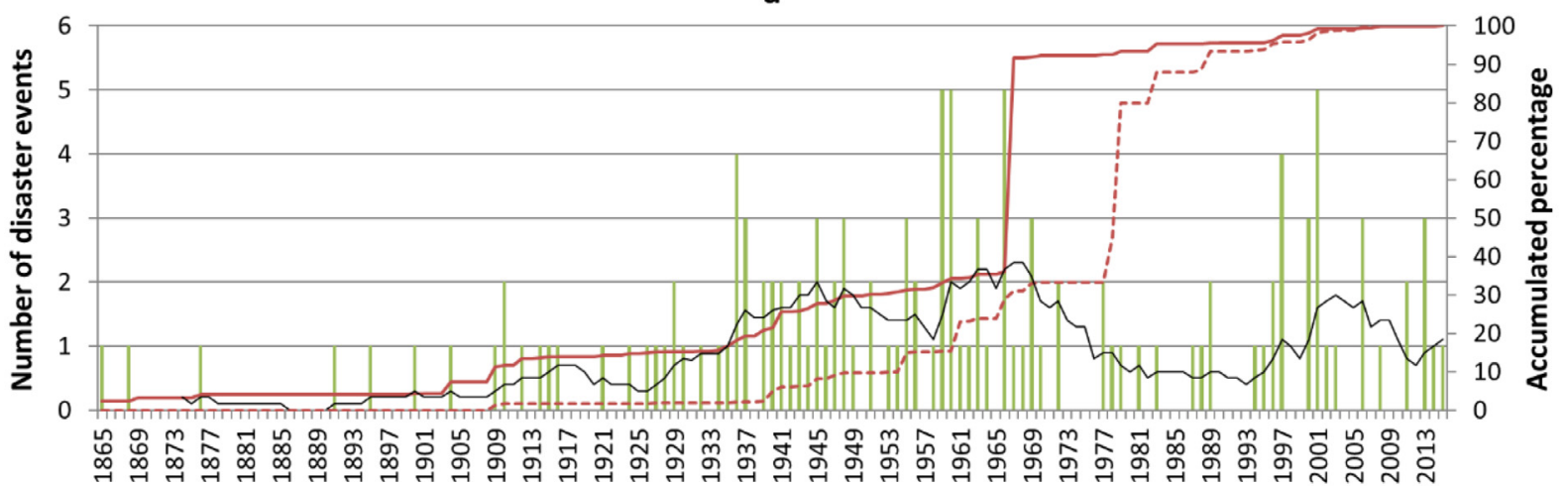

Disaster events _-Fatalities ----Displaced people —Disaster events moving average (10 years)

b

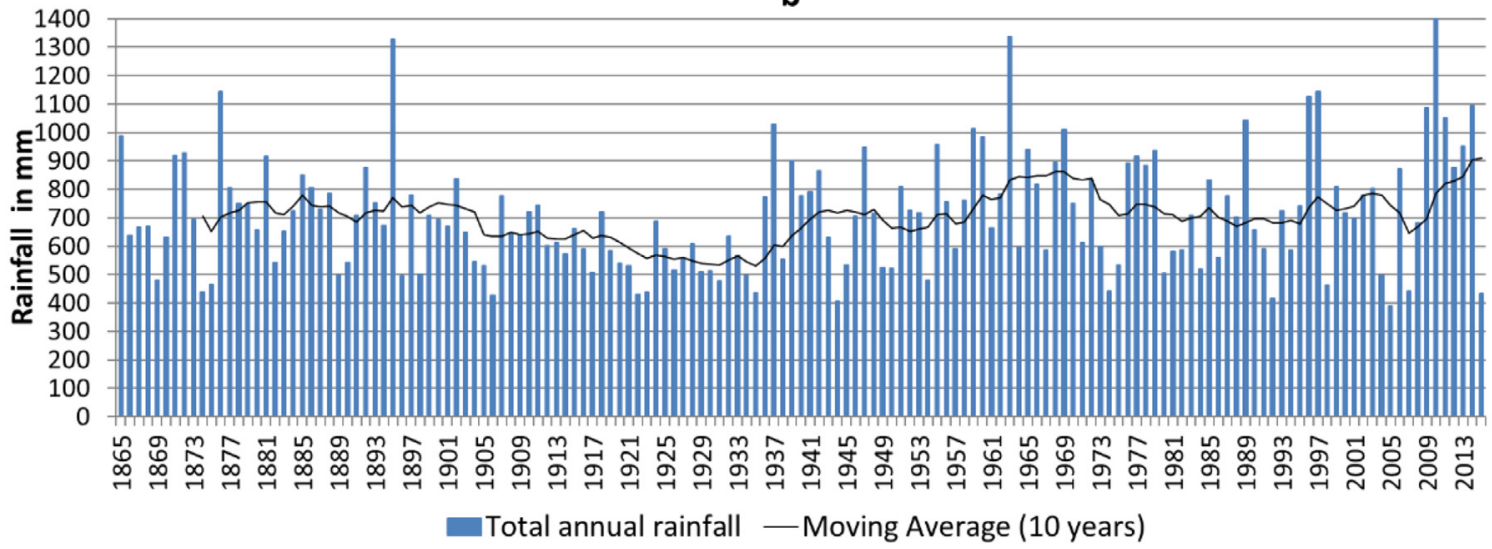

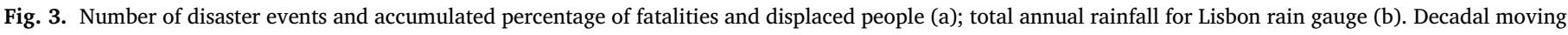
average for disaster events and total annual rainfall is also represented.

fected each individual district and the total set of disaster events (130) observed in the country. The disaster events that affected more than one district ( $77.7 \%$ of total disaster events) were divided by the number of evolved districts to guarantee the consistency of the computed percentages. The percentage of disaster events that affected each district is represented in order to be compared with the CWT results. In addition, the affected districts by each disaster event are listed in Table A in Appendix.

The highest number of affected people (sum of fatalities, injured, evacuated and displaced people) by disaster events (Fig. 4) was recorded in the districts of Santarém, Lisbon and Vila Real. The high number of affected people in Santarém and Vila Real is mainly justified by the displaced people due to the Tagus and Douro rivers floods, whereas the Lisbon district feature is justified by the highest population density in the country, enhancing hydro-geomorphological risk exposure, particularly in suburban municipalities close to Lisbon (Trigo et al., 2016). On opposite, the districts of Évora, Portalegre, Castelo Branco and Guarda are located in the inner country and have a low population density, which largely justifies the low number of affected people by hydrogeomorphological disasters (less than 100 affected people by disaster events for the complete period).

The population exposure is also an important factor to explain the percentage of disaster events in the country. Lisbon district where the national capital is located was affected by 63 disaster events, whereas the Porto district that contains the second most large city of the country was affected by 56 disaster events. Again, the less populated districts of Beja, Évora and Portalegre recorded less than 3\% of the disaster events.

\subsection{Circulation weather types}

It has been shown that the use of the CWTs can represent an important tool in explaining rainfall not only at a daily scale but also at a monthly and annual scales in Portugal (Cortesi et al., 2014; Ramos et al., 2014a, b; Trigo and DaCamara, 2000). The most frequent CWT is the A (32.7\%) along with the E type (above 15\%). Regarding the CWTs that are usually associated to rainfall in Portugal the $C$ type has a frequency of near $7 \%$ while the SW/W/NW combine $24 \%$ of the annual frequency.

Regarding the days of the disaster events the annual average frequency of CWT's shows different results controlled by wet CWT's. In this case the combination of the SW, NW and W corresponds to $72.8 \%$ of the number of days with disaster events, followed by the combined classes E, SE and S (13.6\%). In addition, the C type corresponds to $6.8 \%$ of days with disaster events. Monthly distribution of the percentage of days with disaster events (Fig. 5) shows a higher frequency of days with disaster events in November, December, January, February and March (late autumn and winter). In those months, the CWTs with a Western component were responsible for $65.8 \%$ of the days with disaster events. Days with Cyclonic weather types that caused disaster events were more frequent in January (2.9\%).

The relationship between the CWT's and the hydrogeomorphological events shows that three CWTs (Cyclonic, Westerly and Southwesterly) are frequently associated with floods and landslides that generated major impacts, such as fatalities and displaced people (Fig. 6).

According to this split analysis considering the influence of each CWT, the Cyclonic was associated to $57 \%$ of the fatalities, while the 


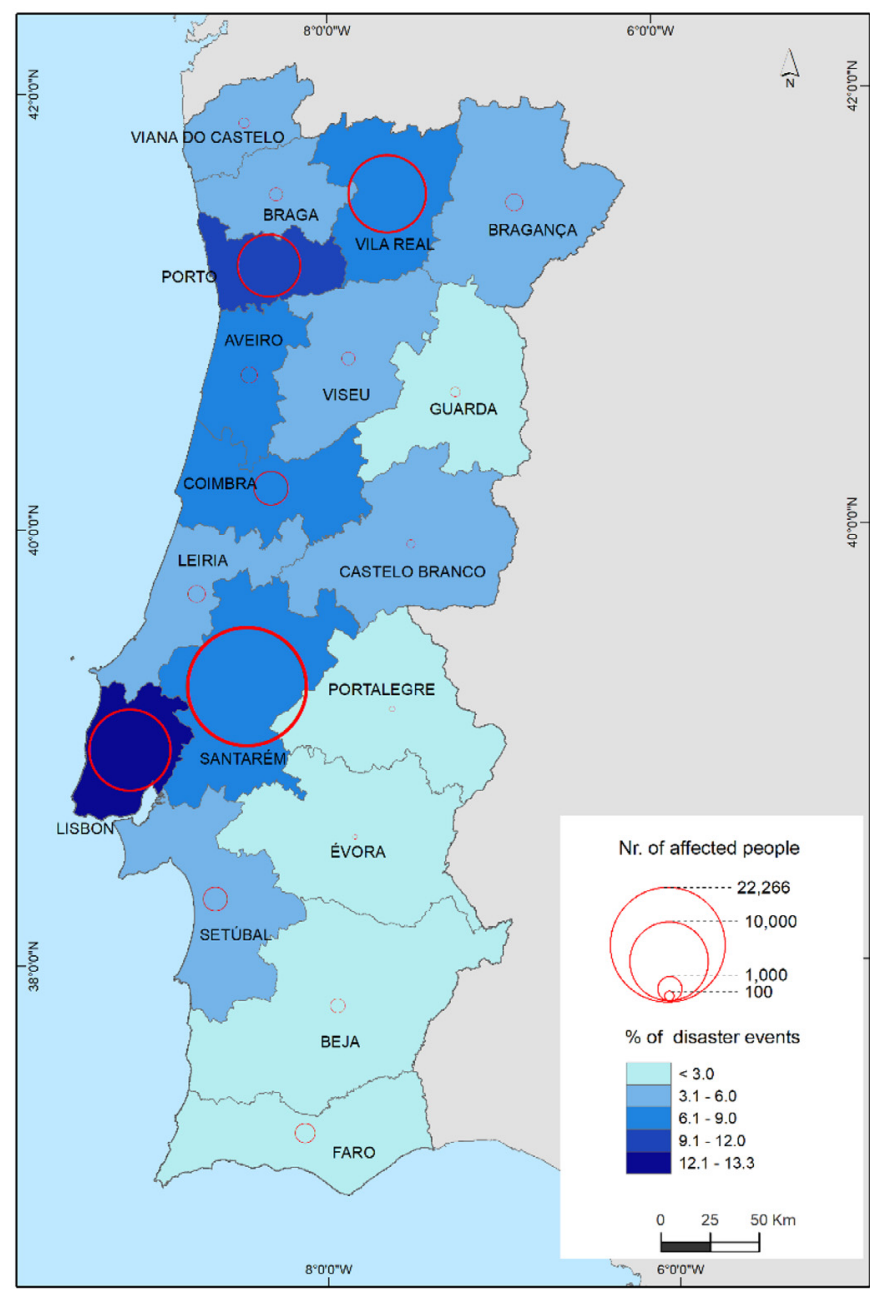

Fig. 4. Number of affected people and percentage of disaster events per district.

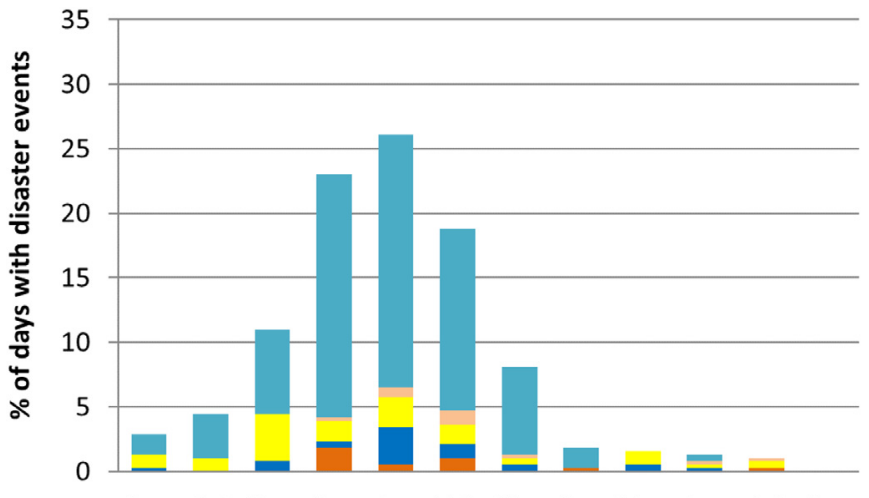

Sep Oct Nov Dec Jan Feb Mar Apr May Jun Jul Aug

$$
\square \mathrm{A} \square \mathrm{C} \square \mathrm{E} / \mathrm{SE} / \mathrm{S} \square \mathrm{NE} / \mathrm{N} \square \mathrm{SW} / \mathrm{W} / \mathrm{NW}
$$

Fig. 5. Percentage of days with disaster events (1865-2015) and the corresponding CWT.

$\mathrm{W}$ is responsible for nearly $49.4 \%$ of the displaced people caused by floods and landslides. The three CWTs characterized by a strong westerly component (SW, W, NW) are associated to $72.6 \%$ of all disaster cases and $77.3 \%$ of displaced people generated by disaster events. Due to the disproportionate impact of a few events in the DISASTER database (see Fig. 3) these results must be carefully analysed in what concerns fatalities or displaced people occurred. For instance, the flash flood event of November 1967 (\#84) caused 522 fatalities, however, when we remove this event from the CWT analysis, the cyclonic type includes only $3.3 \%$ of fatalities, while SW and W raise their impact significantly (36.1 and $38.3 \%$, respectively). Likewise, if we remove the 14,322 displaced people, related with the extreme event of February 1979 (\#95) from this analysis, the westerly component CWTs frequency includes $65.2 \%$ of displaced people (36.9\% for SW, $26.2 \%$ for W and 2.1 for NW).

The atmospheric circulation associated preferentially with floods and landslides types was also discriminated according to the preferred CWTs (Fig. 7). Near half of the floods are associated with either W or SW (Fig. 7a), that generated several rainy days during winter months, like for example in the disaster events of December 1989 (\#101) and

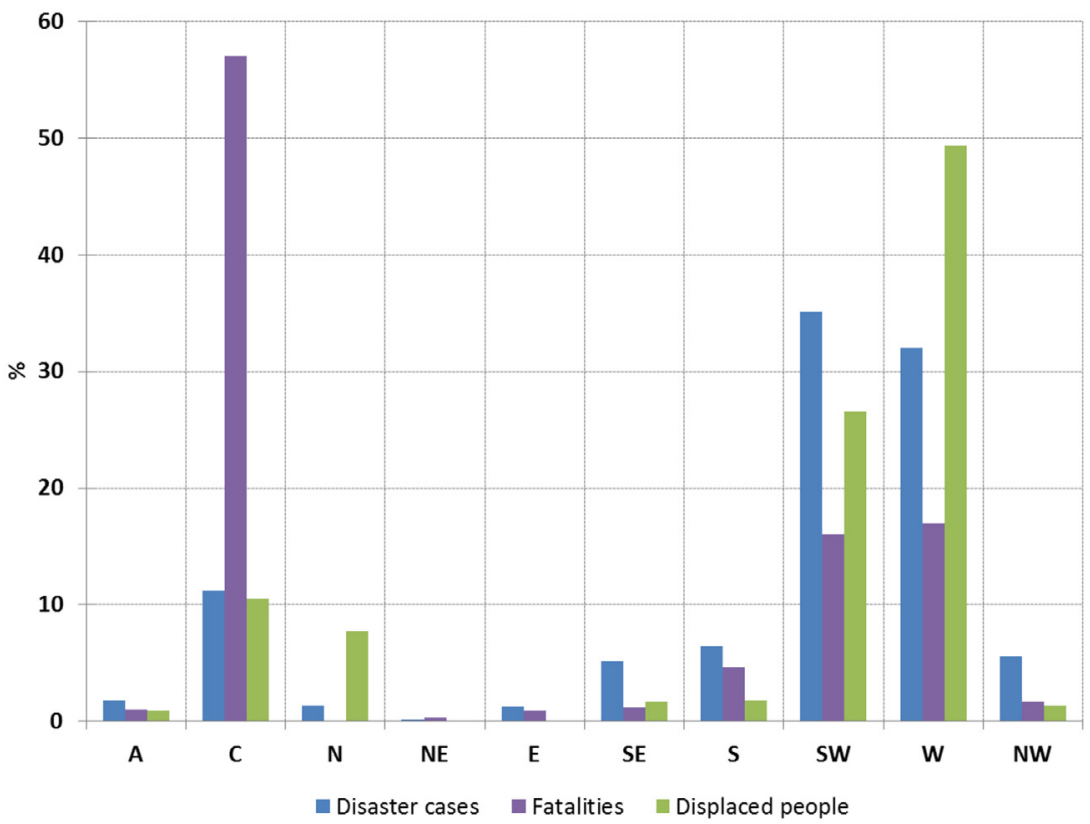

Fig. 6. Percentage of disaster cases, fatalities and displaced people according to the CWT of the total set of disaster events. 

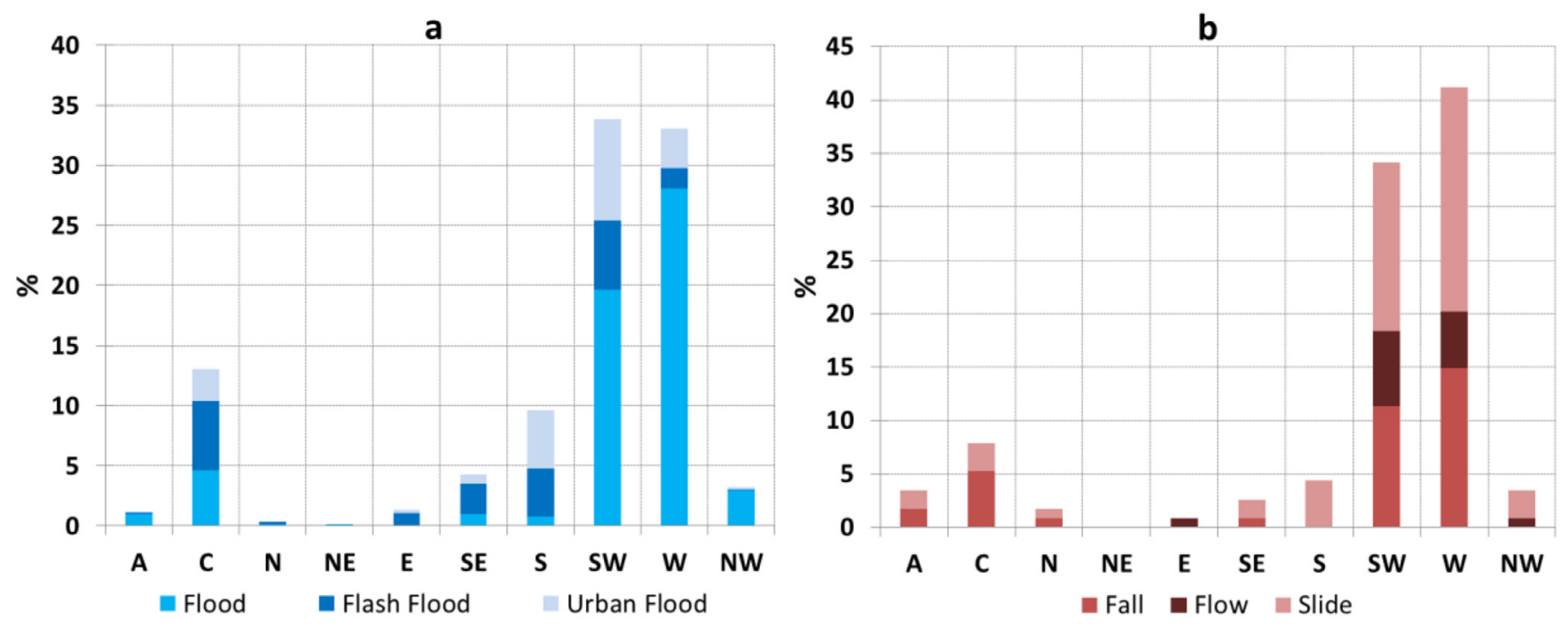

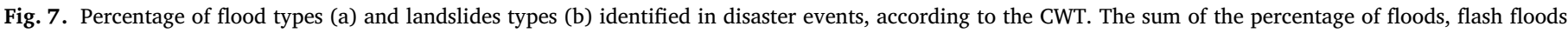
and urban floods by CWT is $100 \%$ (a); the sum of the percentage of falls, flows and slides by CWT is $100 \%$ (b).

February 1979 (\#95) with 12 days of duration both. Flash floods are often associated to $\mathrm{C}$ and SW class because these CWTs can generate short duration rainy events with large amounts of rainfall, such as during the disaster events of November 1967 (\#84) and November 1983 (\#97). Cyclonic weather types were previously associated with flash floods in different basins in the North and South of Portugal (Santos et al., 2017).

In Portugal, rainfall is the main triggering factor of landslides, and landslides have been typically associated with rainy periods lasting from few days to several weeks (Trigo et al., 2005; Vaz et al., 2018; Zêzere et al., 2015). These rainy periods are potentially associated with CWTs with a western component (SW and W, see Fig. 7b). The January 2001 (\#114) is an example of a disaster event characterized by several damaging landslides in the North and Centre of Portugal. In few cases, landslides were recorded in days with Anticyclonic CWT, but the triggering rainfall certainly occurred in previous days (most likely during a rainy CWT) or, alternatively, it can be related with a delay in the landslide report.

In spatial terms, Lisbon and Porto districts recorded the highest number of disaster events (107), whereas Portalegre only includes 9 days with disaster events in the total studied period (Fig. 8).

CWTs with the westerly component (SW, W, NW) corresponded to more than $90 \%$ of the days with disaster events in Aveiro, Braga and Vila Real (Fig. 8). During rainy months, these districts are frequently under the influence of the Western circulation preferentially associated with an atmospheric circulation pattern consisting of high pressure centred west of the Canary Islands and a low-pressure system located north of the Iberian Peninsula. Consequently, the cold and warm fronts associated with these westerly flows enter in the IP reaching the mountain arch affecting the entire Portugal with rainfall but particularly the northern and central sectors. In addition, the $\mathrm{C}$ type also produces rainfall since the low-pressure systems associated with this type are located over Portugal (Ramos et al., 2014a; Trigo and DaCamara, 2000). On the contrary, the impact of easterly component types (E/SE/S) is observed more frequently in the southern districts of Faro and Beja that are more affected by cut-off low systems (Nieto et al., 2007) which have SE and S types signature at surface and are responsible for convective precipitation when this kind of types occurred. The E type is usually associated to the summer month's deep convection mainly due to the thermal low that developed over the Iberian Peninsula (Hoinka and Castro, 2003).

Therefore, we have shown in Fig. 8, the CWT responsible for the disaster events are divided into two main areas, the central and northern Portugal where the main drivers are associated to the SW, W, NW and
C types responsible for more than $2 / 3$ of the disaster events, while for the southern (mostly Beja and Faro districts) the E, SE and S emerge as the main drivers, albeit associated with significantly less total events in those districts.

\subsection{Was rainfall the main driving force of disaster events?}

Having characterized the preferred atmospheric circulation patterns of the disaster events, in terms of circulation weather types we focus our attention on the assessment of the importance of the rainfall as a driving force of the disaster events in Portugal.

It was shown by Ramos et al. (2015) that the ARs are responsible for the most extreme rainfall days in the Iberian Peninsula and particularly in Portugal. Here we analyse the importance of the ARs in terms of human damages especially in terms of increased mortality but also in the number of people injured and disappeared. Taking into account the large amount of water vapour transported by the ARs and the fact that these long and narrow low troposphere structures have an impact in extreme rainfall in Portugal, we have also analysed for each disaster event the presence (or absence) of ARs (see Table A in the Appendix section). Results show for the 130 events considered in the DISASTER database circa $45 \%$ of them are indeed associated to the presence of ARs, corresponding to $34 \%$ of the total days of the events. In terms of human impacts, the ARs days are linked to extreme events responsible for $21 \%$ of the fatalities, $18 \%$ of the injured, $20 \%$ of the evacuated and $16 \%$ of the displaced people. However, the extreme disaster event of November 1967 flash flood event (\#84) already mentioned in Section 3a, includes $55.7 \%$ of the total fatalities and $57.6 \%$ of injured people included in the complete set of disaster events. During this extreme event no ARs were responsible for the extreme rainfall that occurred during that day as shown by Trigo et al. (2016). If we remove this event from the database, the percentage of fatalities and injured people that occurred during disaster events associated with ARs increases to $47 \%$ of the total dead toll and $42 \%$ in the injured people. For the remaining impacts (evacuated, displaced and disappeared people) no significant changes occur. Therefore, the importance of ARs in terms of human damages is even higher as explained before when we not take into account the November 1967 (\#84) extreme event.

In order to evaluate the importance of rainfall as driving force of the disaster events in Portugal we looked in depth to the accumulated rainfall percentiles of the climatological year. The accumulated rainfall percentile of the first day the event ranges from 2 until 99 percentiles 


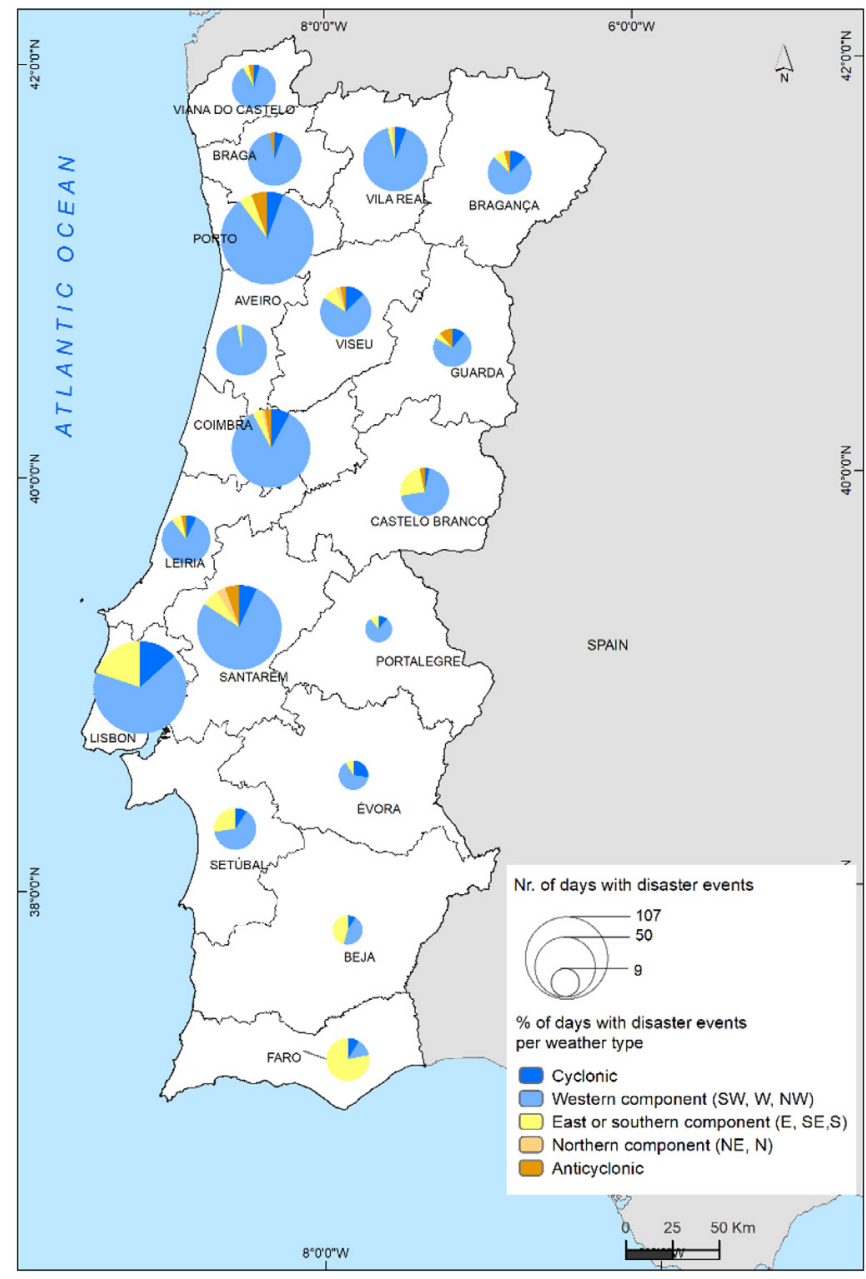

Fig. 8. Number of days with disaster events and percentage of days per CWT.

and has a mean value of 68.2. Events \#3 and \#29 that correspond to floods and landslides recorded the highest values of initial rainfall percentiles (99) present a probability $\leq 0.05$ following the Generalized Extreme Values probability fit distribution.

In addition, the accumulated rainfall percentile achieved at the end of the events has a good fit to a Generalized Pareto distribution, ranging from 5 until 99 percentiles and has a mean value of 77.1. According to this distribution, 10 disaster events were identified with a probability $\leq 0.01$ in the rainfall percentile achieved at the end of the events (\#3, \#11, \#19, \#23, \#28, \#29, \#32, \#95, \#101, \#107, \#109, \#120).

The increase in the accumulated rainfall percentile during the event ranges from 0 until 78, with a mean of 8.9 and has a good fit to a Generalized Extreme Values distribution. According to this distribution results, 9 disaster events were identified with a probability $\leq 0.05$ in the increase in the accumulated rainfall percentile during the event ( $\# 19$, $\# 30$, \#37, \#45, \#51, \#58, \#59, \#62). The event \#19 registered the highest increase in the accumulated rainfall percentile during the event (78) with a probability of 0.005 .

We will now look in detail to the 20-28 December 1909 disaster event (\#8) as an example (Fig. 9) to show the importance of the accumulated rainfall. In the first day of the event, the accumulated rainfall for that climatological year corresponds to the 87th percentile while at the last day of the event the 97th percentile was reached. The CWT where dominated by $\mathrm{W}$ and SW days when most of rainfall occurred. In addition, in this event, the landfalls of ARs in Portugal have enhanced the anomalous rainfall that occurred during the event (Pereira et al.,
2016). For all the reasons mentioned above, the atmospheric driving mechanisms were very important to explain this disaster event.

When the complete set of disaster events is analysed taking into account the accumulated rainfall percentile in the first day and in the last day of the event (Fig. 11a) for the climatological year of each disaster event, 29 disaster events can be characterized by rainfall percentiles $>90$ th at the beginning of the events. In this case, there are no doubts that accumulated rainfall is very important to trigger disaster events associated with floods and landslides. A hierarchical cluster analysis of the accumulated rainfall percentiles that characterize each disaster event (first day, last day and increase in the rainfall percentile) allowed the identification of four clusters (Fig. 10b) and the presence of ARs is also shown.

Cluster 1 includes 69 disaster events (53.3\% of total events) generated by long lasting rainfall events with the highest initial accumulated rainfall percentile starting in the 70th percentile and the last accumulated rainfall ranges from 78th-99th percentiles (Table 4). Additionally, roughly $(47.8 \%)$ of the events belonging to this cluster were characterized by the presence of ARs. Disaster floods and landslides were mainly located north of the Tagus River. Due to these reasons the amount of rainfall and the associated atmospheric mechanisms can be considered a very important driving force of disaster events included in cluster 1.

In cluster 2 accumulated rainfall can be considered an important triggering factor, including $29.5 \%$ of the disaster events (Table 4 ). The accumulated rainfall percentile at the beginning of the events of cluster 2 ranges from the 37 th-73th percentiles and increase to 48th-86th percentiles at the end of the events. Additionally, $42 \%$ of the disaster events included in this cluster had the presence of ARs and include floods, urban floods and landslides.

Cluster 3 includes disaster events with low initial accumulated rainfall percentile (ranging from 14th-49th percentiles) but registering the highest increase in the accumulated rainfall percentile during the event (43.7 average rising) and all events included in this cluster were characterized by the presence of ARs. Cluster 3 includes flash floods and urban floods.

Cluster 4 includes disaster events with the lowest accumulated rainfall percentiles at the beginning and the end of the events and only two events of this cluster are associated with ARs (Table 4). The cluster 4 contains flash floods and urban floods generated by localized convective systems that are not reflected in the accumulated rainfall. Damaging floods and landslides can be related to other driving forces such as risk exposure and land use. In this case, the role of accumulated rainfall as the triggering factor of disaster events is very small, if any.

\subsection{Disaster events catalog}

A comprehensive catalogue containing all disaster events was created including details about the human damage features (total affected people, displaced people, evacuated people, injured and fatalities); number of floods and landslides and a map with points representing cases belonging to each event obtained from the DISASTER database. This catalogue also includes the mean accumulated rainfall $(\mathrm{mm})$ and the corresponding 10th, 50th, 90th, 95th and 99th percentiles for the complete climatological year (1 September-31 August) and the presence of ARs for all disaster events obtained in Section 2.3.

Dominant circulation weather types recorded during the event and days with ARs are also included in this catalogue, including some images of the atmospheric circulation for previous days of the event and days during the event obtained in Section 2.4. The events catalogue is available online and can be downloaded at http://www.ceg.ulisboa.pt/forland/en/ (website available in English). Fig. 11 shows an example of the 20-28 December 1909 included in this catalogue. 
(a)

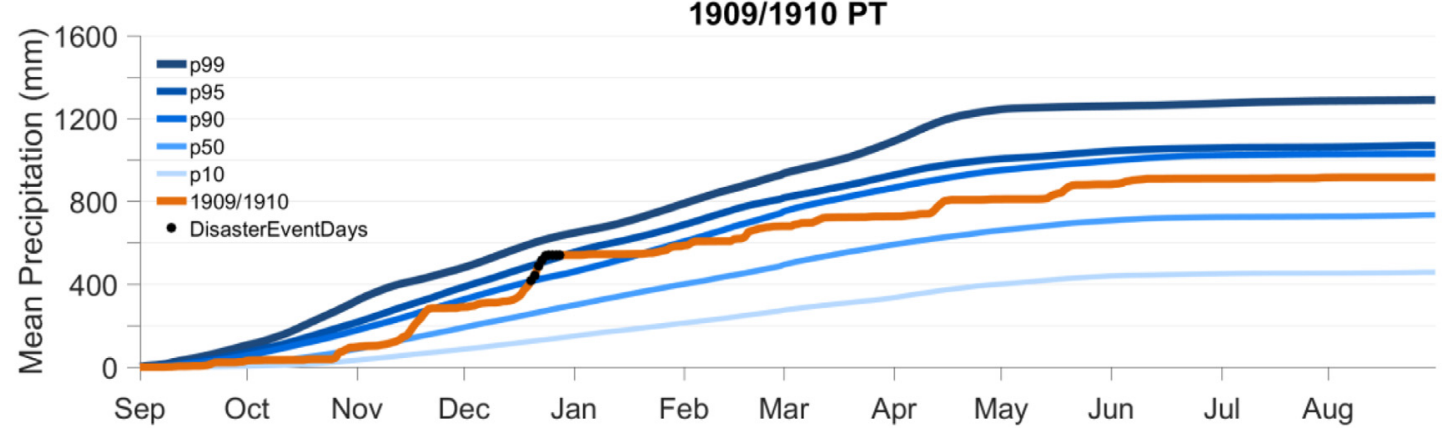

(b)

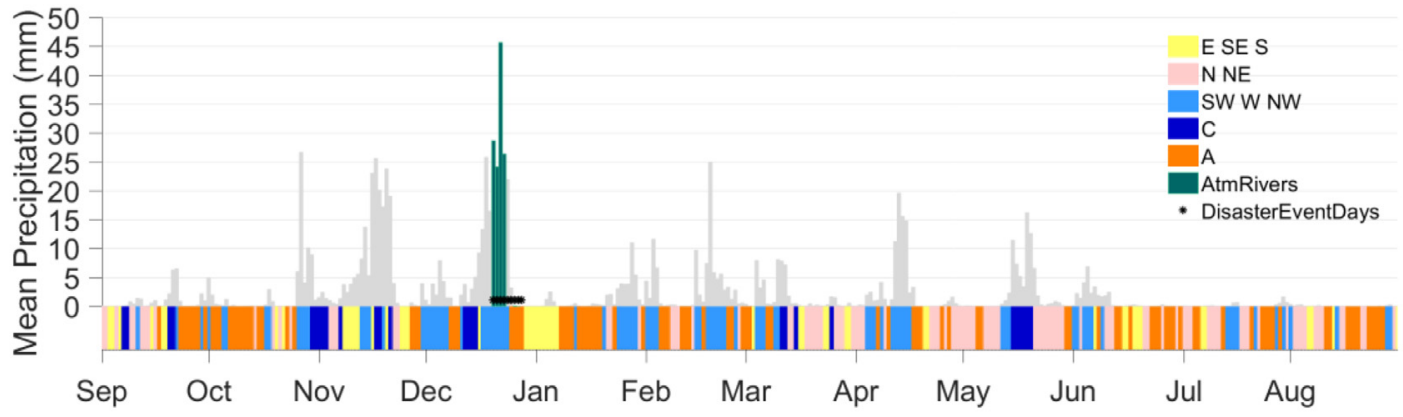

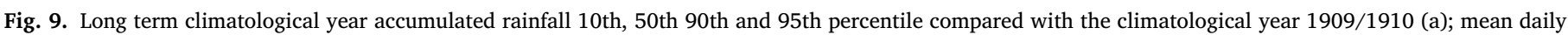

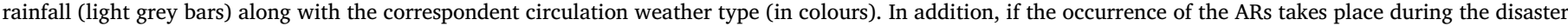

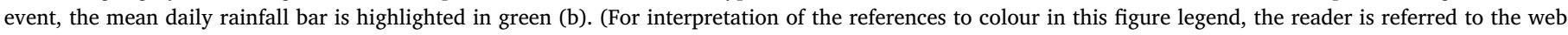
version of this article.)

a

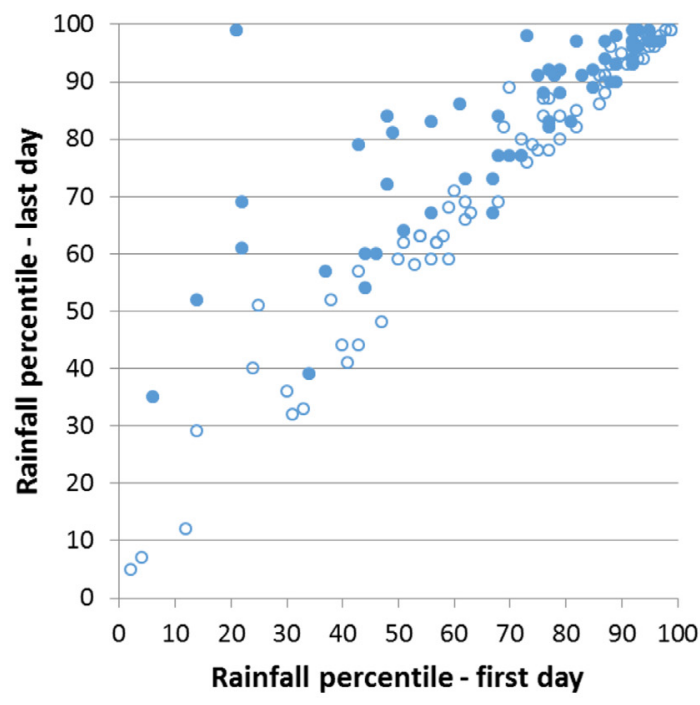

o Disaster events - Disaster events ARs b

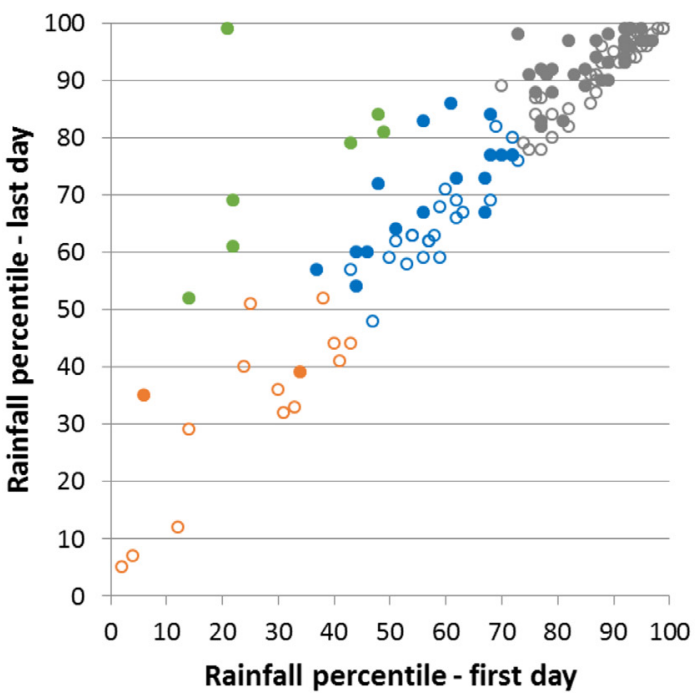

o Cluster $1 \quad$ o Cluster $2 \quad$ OCluster $3 \quad$ Cluster 4

- Cluster 1 ARs - Cluster 2 ARs - Cluster 3 ARs $\bullet$ Cluster 4 ARs

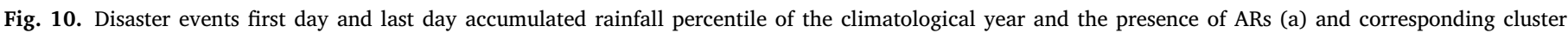
analysis (b) with the ARs associated with each disaster event.

\section{Conclusions}

This work updated the DISASTER database and the catalogue of flood and landslide disaster events that caused human damages in Portugal in the period 1865-2015. Disaster events definition was based on 3 criteria (the disaster event should include at least 3 disaster cases; any disaster event should be bound by 3 consecutive days without recorded disaster cases; and disaster events must be located within a relatively continuous spatial pattern devoid of isolated disaster cases). We acknowledge that these criteria may be discussable, but since we are dealing only with damaging floods and landslides referred to in the newspapers, these criteria showed to be efficient in removing isolated disaster cases in temporal and spatial terms. 


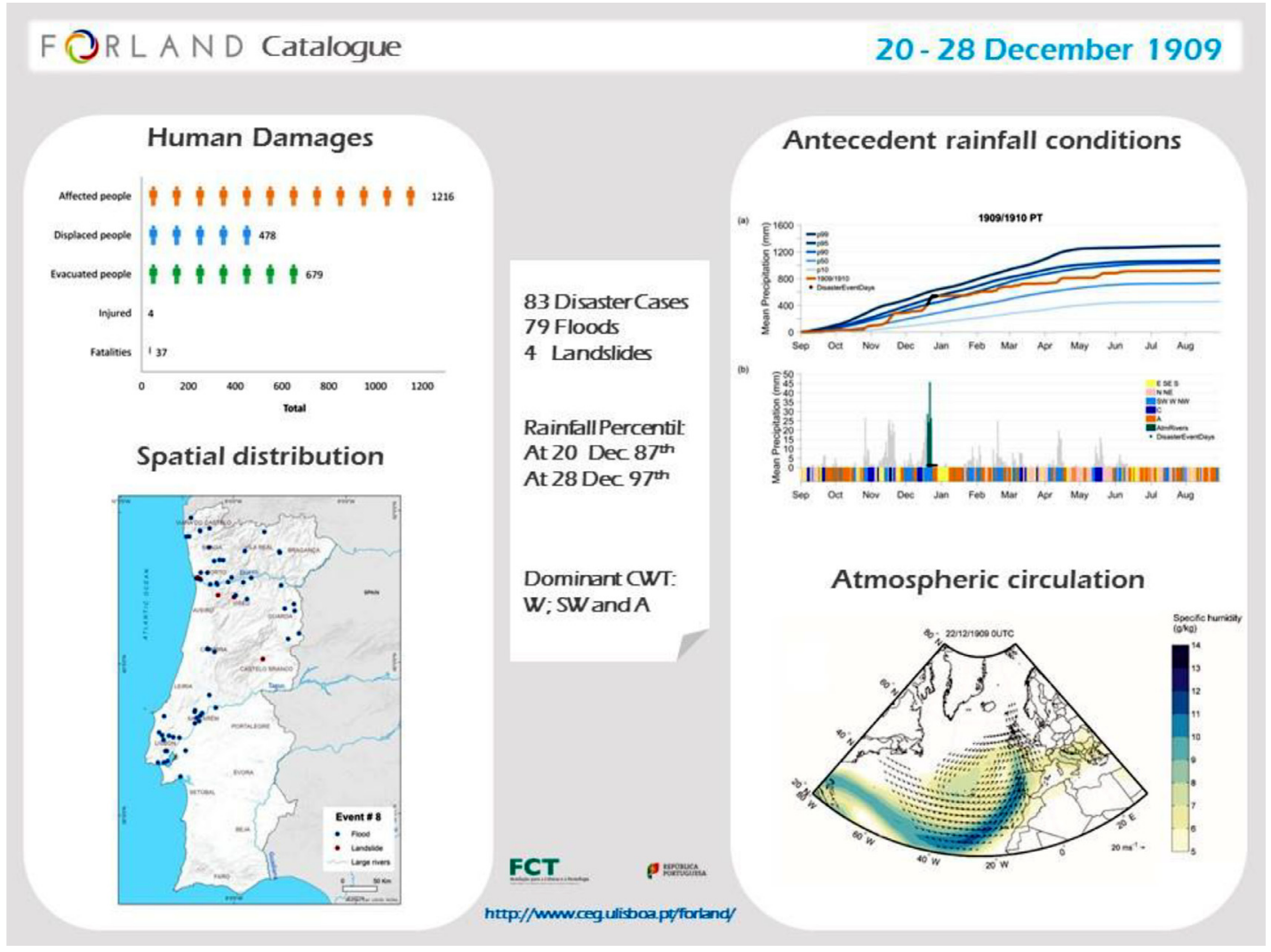

Fig. 11. Example of the 20-28 December 1909 disaster event in the FORLAND catalogue.

A set of 130 hydro-geomorphologic disaster events occurred in Portugal during the period 1865-2015 was characterized, and extreme and outlier disaster events were identified in terms of number of disaster cases, duration in days, and number of fatalities, injured, evacuated and displaced people. This catalogue includes for the first time the associated CWTs, as well as information about the presence or absence of ARs for all the disaster events documented for a 150-years period. Additionally, it also provides the long-term accumulated rainfall 10th, 50th 90th and 95th percentile for all climatological years.

Temporal trends of disaster events show that the number of fatalities and displaced people has been driven by specific extreme events. Moreover, the spatial distribution of disaster events is controlled either by the presence of flood and landslides predisposing factors, by the population exposure, and by the spatial incidence of the particular rainfall triggering mechanism (Trigo et al., 2016). Indeed, the occurrence of disasters resulting from flood and landslide events, like those listed in the DISASTER database, depends not only on the rainfall trigger but also on other drivers that include the spatial distribution of predisposing factors that control the flood and landslide susceptibility, as well as the increasing exposure associated with land use change and the social and territorial vulnerability (Guillard-Gonçalves et al., 2014; Pereira et al., 2016; Santos et al., 2014, 2018; Tavares et al., 2012; Zêzere et al., 2018). However, the rainfall triggered all the hydro-geomorphological disaster events collected in the DISASTER database and listed in the catalogue. The relation between rainfall and floods is direct taking in account the typical pluvial regime of the rivers and the negligible effect of snowmelt. In the case of landslides, previous extensive work has demonstrated the role of rainfall as major landslide trigger in Portugal (e.g. Trigo et al, 2005; Vaz et al., 2018; Zêzere et al., 2005, 2015). Moreover, landslides triggered by earthquakes in Portugal were recently summarized by Vaz and Zêzere (2015) and were not considered in this study. Therefore, the main research question to be raised was not if disaster events were triggered by rainfall, but to what extent the magnitude of the registered hu- man consequences can be explained by the exceptionality of the rainfall triggering.

The importance of the rainfall accumulated before and during each event was assessed using the 20CR dataset. According to our experience in previous works (Rebelo et al., 2018; Trigo et al., 2016), we acknowledge that the detailed study of disaster events demands the use of detailed rainfall datasets such as daily precipitation for the Iberian Peninsula using the IB02 (Ramos et al., 2014b) starting in 1950 and EraInterim Reanalysis starting in 1979, always combined with long timeseries of instrumental daily records. Furthermore, this work was already performed for a limited set of major events (December 1876; December 1909; November 1967 and February 1979). Even using a coarser precipitation dataset, it was possible to evaluate and compare the previous rainfall conditions of each disaster event.

Even knowing that the rainfall conditions of the disaster events deserve a local and detailed analysis it was possible to identify a set of disaster events where the rainfall was the main driving force with a high degree of confidence (Cluster 1) and an important role of this driving force that might be combined with other driving forces in Clusters 2 and 3 (e.g. atmospheric forcing combined with physical predisposing factors of floods and landslides, and population exposure). Disaster events of Cluster 4 clearly show a low importance of the accumulated rainfall but the human damages can be related to other driving forces such as land use changes and people exposure to risk.

We concluded that the number of disaster events is mainly associated with SW and W weather types in their genesis. In the central and northern Portugal disaster events are mainly driven by CWTs with a westerly component (SW, W, NW) and also the Cyclonic class C, while in the southern districts the $\mathrm{E}, \mathrm{SE}$ and $\mathrm{S}$ types are the main drivers. Cyclonic CWT is also associated with convective systems that generate flash floods and urban floods, especially in the South of the country (Santos et al., 2017) and were responsible for high direct human damages such as fatalities and injured people (Trigo et al., 2016). Westerly 


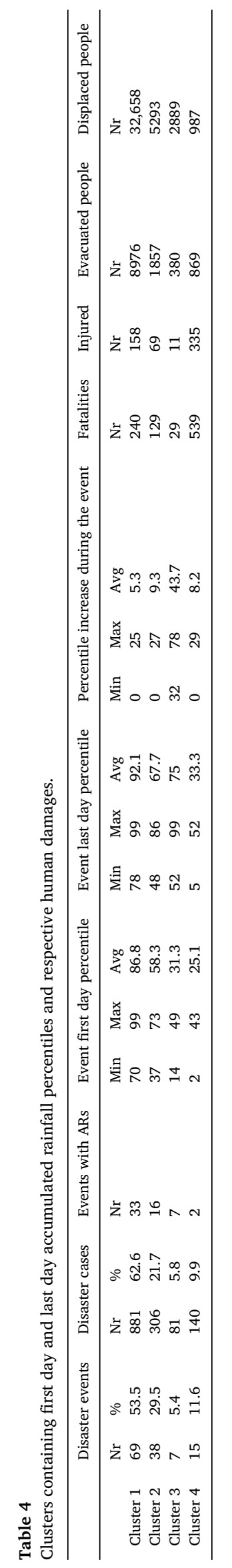

CWTs usually generate prolonged wet periods characterized by several days or weeks with flood events in the main rivers. As a consequence, these events are responsible for high numbers of displaced people in the riverine villages. Large slides and debris flows also are associated with long rainy periods. These differences can be related to the most frequent weather types in each region: North and Center regions are more affected by low pressure systems and their associated frontal systems usually located northwest the Iberia Peninsula, whereas the Southern region is more affected by cut-off low pressure systems or mesoscale convective systems. Also the presence of Atmospheric Rivers over the country was assessed for each disaster event, because it can enhance the precipitation amount along its passage over land. Regarding the 130 events analysed here it was shown that circa $45 \%$ of them are associated to the presence of ARs, corresponding to $34 \%$ of the total days of the events. In terms of human impacts, the ARs days are linked to extreme events responsible for $21 \%$ of the fatalities, $18 \%$ of the injured, $20 \%$ of the evacuated and $16 \%$ of the displaced people.

The disaster events catalogue is an important historical and meteorological data source of the damaging floods and landslides that occurred in Portugal in a 150-year period. This new catalogue allows for the ranking of disaster events in the country in terms of human damages and the type of meteorological system that triggered the events. In addition, the catalogue is used to identify those events that generated higher impacts in populations and settlements along time and space, contributing to the further detailed study of the events at national and Iberian scale (e.g. Pereira et al., 2016; Trigo et al., 2014), and to the civil protection authorities to associate the predicted CWT with the generation of specific hydro-geomorphological events and associated types of damage.

The methodology used to build the DISASTER database and the disaster events catalogue can be applicable to other study areas where floods and landslides are mostly associated with the atmospheric circulation, as is the case of the North Atlantic and the Mediterranean regions.

\section{Acknowledgments}

This work was financed by national funds through FCT-Portuguese Foundation for Science and Technology, I.P., under the framework of the project FORLAND-Hydro-geomorphologic risk in Portugal: driving forces and application for land use planning [PTDC/ATPGEO/1660/2014]. A. M. Ramos was also supported by a FCT postdoctoral grant [FCT/DFRH/ SFRH/BPD/84328/2012].

\section{Supplementary materials}

Supplementary material associated with this article can be found, in the online version, at doi:10.1016/j.advwatres.2018.10.001.

\section{References}

Barnolas, M., Llasat, M.C., 2007. A flood geodatabase and its climatological applications: The case of Catalonia for the last century. Nat. Hazards Earth Syst. Sci. 7, 271-281.

Compo, G.P., Whitaker, J.S., Sardeshmukh, P.D., Matsui, N., Allan, R.J., Yin, X., Gleason, B.E., Vose, R.S., Rutledge, G., Bessemoulin, P., Brönnimann, S., Brunet, M., Crouthamel, R.I., Grant, a.N., Groisman, P.Y., Jones, P.D., Kruk, M.C., Kruger, a.C., Marshall, G.J., Maugeri, M., Mok, H.Y., Nordli, Ø., Ross, T.F., Trigo, R.M., Wang, X.L., Woodruff, S.D., Worley, S.J., 2011. The Twentieth Century Reanalysis Project. Q. J. R. Meteorol. Soc 137, 1-28. https://doi.org/10.1002/qj.776.

Cortesi, N., Gonzalez-Hidalgo, J.C., Trigo, R.M., Ramos, A.M., 2014. Weather types and spatial variability of precipitation in the Iberian Peninsula. Int. J. Climatol. 34, 26612677. https://doi.org/10.1002/joc.3866.

Cortesi, N., Trigo, R.M., Gonzalez-Hidalgo, J.C., Ramos, a.M., 2013. Modelling monthly precipitation with circulation weather types for a dense network of stations over Iberia. Hydrol. Earth Syst. Sci. 17, 665-678. https://doi.org/10.5194/hess-17-665-2013.

Dettinger, M., Ralph, F., Lavers, D., 2015. Setting the Stage for a Global Science of Atmospheric Rivers. Eos, Washington. DC, p. 96. https://doi.org/10.1029/2015EO038675.

Devolli, G., Jørandli, L., Engeland, K., Tallaksen, L.M., 2017. Large-scale synoptic weather types and precipitation responsible for Landslides in Southern Norway. In: Sassa, K., Mikos, M., Yin, Y. (Eds.), Advancing Culture of Living with Landslides. Springer, pp. 159-167. https://doi.org/10.1007/978-3-319-53485-5_17.

EM-DAT [WWW Document], 2016. OFDA/CRED Int. Disaster Database, Cathol. Univ. Louvain, Brussels, Belgium URL www.emdat.be . 
Fragoso, M., Marques, D., Santos, J., Alcoforado, M., Amorim, I., Garcia, J., Silva, L., Nunes, M., 2015. Climatic extremes in Portugal in the 1780s based on documentary and instrumental records. Clim. Res. 66, 141-159. https://doi.org/10.3354/cr01337.

Fragoso, M., Trigo, R.M., Pinto, J.G., Lopes, S., Lopes, A., Ulbrich, S., Magro, C., 2012. The 20 February 2010 Madeira flash-floods: synoptic analysis and extreme rainfall assessment. Nat. Hazards Earth Syst. Sci 12, 715-730. https://doi.org/10.5194/nhess-12-715-2012.

Fragoso, M., Trigo, R.M., Zêzere, J.L., Valente, M.A., 2010. The exceptional rainfall event in Lisbon on 18 February 2008. Weather 65, 31-35. https://doi.org/10.1002/wea.513.

Gilabert, J., Llasat, M.C., 2017. Circulation weather types associated with extreme flood events in Northwestern Mediterranean. Int. J. Climatol 38, 1864-1876. https://doi.org/10.1002/joc.5301.

Guha-Saphir, D., Vos, F., et al., 2011. Quantifying global environmental change impacts: methods, criteria and definitions for compiling data on hydro-meteorological disasters.. In: Brauch, H., et al. (Eds.), Coping with Global Environmental Change, Disasters and Security, Hexagon Series on Human and Environmental Security and Peace. Springer, Berlin.

Guha-Sapir, D., Hoyois, P., Below, R., 2014. Annual Disaster Statistical Review 2011: The numbers and trends, Annual Disaster Statistical Review 2011 - The numbers and trends. doi:10.1093/rof/rfs003.

Guillard-Gonçalves, C., Cutter, S.L., Emrich, C.T., Zêzere, J.L., 2014. Application of Social Vulnerability Index (SoVI) and delineation of natural risk zones in Greater Lisbon, Portugal. J. Risk Res. 18, 651-674. https://doi.org/10.1080/13669877.2014.910689.

Guzzetti, F., Tonelli, G., 2004. Information system on hydrological and geomorphological catastrophes in Italy (SICI): A tool for managing landslide and flood hazards. Nat. Hazards Earth Syst. Sci. 4, 213-232. https://doi.org/10.5194/nhess-4-213-2004.

Hoinka, K.P., Castro, M.de, 2003. The Iberian Peninsula thermal low. Q. J. R. Meteorol. Soc 129, 1491-1511. https://doi.org/10.1256/qj.01.189.

IPCC, 2012. Managing the Risks of Extreme Events and Disasters to Advance Climate Change Adaptation, Special Report of the Intergovernemental Painel on Climate Change. Cambridge University Press, Cambridge. https://doi.org/10.1017/CBO9781139177245.

Jenkinson, A.F., Collinson, F.P., 1977. An initial Climatology of Gales over the North Sea. Synop. Climatol. Branch Memo 62.

Kalnay, et al., 1996. The NCEP/NCAR 40-year reanalysis project. Bull. Amer. Meteor. Soc 437-470.

Kutiel, H., Trigo, R.M., 2014. The rainfall regime in Lisbon in the last 150 years. Theor. Appl. Climatol. 118, 387-403. https://doi.org/10.1007/s00704-013-1066-y.

Lamb, H.H., 1972. British Isles weather types and a register of daily sequence of circulation patterns. Geophys. Mem. 116, 1861-1971.

Lavers, D.A., Allan, R.P., Villarini, G., Lloyd-Hughes, B., Brayshaw, D.J., Wade, A.J., 2013. Future changes in atmospheric rivers and their implications for winter flooding in Britain. Environ. Res. Lett. 8, 8. https://doi.org/10.1088/1748-9326/8/3/034010.

Lavers, D.A., Allan, R.P., Wood, E.F., Villarini, G., Brayshaw, D.J., Wade, A.J., 2011. Winter floods in Britain are connected to atmospheric rivers. Geophys. Res. Lett. 38. https://doi.org/10.1029/2011GL049783.

Lavers, D.A., Villarini, G., 2015. The contribution of atmospheric rivers to precipitation in Europe and the United States. J. Hydrol. 522, 382-390. https://doi.org/10.1016/j.jhydrol.2014.12.010.

Lavers, D.A., Villarini, G., 2013. The nexus between atmospheric rivers and extreme precipitation across Europe. Geophys. Res. Lett. 40, 3259-3264. https://doi.org/10.1002/grl.50636.

Lavers, D.A., Villarini, G., Allan, R.P., Wood, E.F., Wade, A.J., 2012. The detection of atmospheric rivers in atmospheric reanalyses and their links to British winter floods and the large-scale climatic circulation. J. Geophys. Res. Atmos. 117, 1-13. https://doi.org/10.1029/2012JD018027.

Liberato, M.L., Ramos, A.M., Trigo, R.M., Trigo, I.F., Durán-Qesada, A.M., Nieto, R., Gimeno, L., Durán-Quesada, A.M., Nieto, R., Gimeno, L., 2013. Moisture sources and large-scale dynamics associated with a flash flood event. In: Lin, J., Brunner, D., Gerbig, C., Stohl, A., Luhar, A., Webley, P. (Eds.), Lagrangian Modeling of the Atmosphere. American Geophysical Union, Washington, D.C., pp. 111-126. http://dx.doi.org/10.1029/2012GM001244.

Ludwig, P., Schaffernicht, E.J., Shao, Y., Pinto, J.G., 2016. Regional atmospheric circulation over Europe during the Last Glacial Maximum and its links to precipitation. J. Geophys. Res. Atmos. 121, 2130-2145. https://doi.org/10.1002/2015JD024444.Received.

Messeri, A., Morabito, M., Messeri, G., Brandani, G., Petralli, M., Natali, F., Grifoni, D., Crisci, A., Gensini, G., Orlandini, S., 2015. Weather-related flood and landslide damage: A risk index for Italian regions. PLoS One 10, 1-17. https://doi.org/10.1371/journal.pone.0144468.

Murtagh, F., Legendre, P., 2014. Ward's hierarchical agglomerative clustering method: Which algorithms implement Ward's Criterion? J. Classif 31, 274-295. https://doi.org/10.1007/s00357-.

Neiman, P.J., Ralph, F.M., Wick, G.A., Lundquist, J.D., Dettinger, M.D., 2008. Meteorological characteristics and overland precipitation impacts of atmospheric rivers affecting the west coast of North America based on eight years of SSM/I Satellite Observations. J. Hydrometeorol. 9, 22-47. https://doi.org/10.1175/2007JHM855.1.

Newelll, E.R., Newell, E.N., Zhu, Y., Scott, C., 1992. Tropospheric rivers?-a pilot study. Geophys. Res. Lett 12, 2401-2404.

Nieto, R., Gimeno, L., Añel, J.A., De la Torre, L., Gallego, D., Barriopedro, D., Gallego, M., Gordillo, A., Redaño, A., Delgado, G., 2007. Analysis of the precipitation and cloudiness associated with COLs occurrence in the Iberian Peninsula. Meteorol. Atmos. Phys. 96, 103-119. https://doi.org/10.1007/s00703-006-0223-6.
Pattison, I., Lane, S.N., 2012. The relationship between Lamb weather types and longterm changes in flood frequency, River Eden, UK. Int. J. Climatol. 32, 1971-1989. https://doi.org/10.1002/joc.2415.

Peña-Angulo, D., Trigo, R.M., Cortesi, N., González-Hidalgo, J.C., 2016. The influence of weather types on the monthly average maximum and minimum temperatures in the Iberian Peninsula. Atmos. Res. 178-179, 217-230. https://doi.org/10.1016/j.atmosres.2016.03.022.

Pereira, S., Diakakis, M., Deligiannakis, G., Zêzere, J.L., 2017. Comparing flood mortality in Portugal and Greece (Western and Eastern Mediterranean). Int. J. Disaster Risk Reduct 22, 147-157. https://doi.org/10.1016/j.ijdrr.2017.03.007.

Pereira, S., Ramos, A.M., Zêzere, J.L., Trigo, R.M., Vaquero, J.M., 2016. Spatial impact and triggering conditions of the exceptional hydro-geomorphological event of December 1909 in Iberia. Nat. Hazards Earth Syst. Sci. 16, 371-390. https://doi.org/10.5194/nhess-16-371-2016.

Promper, C., Gassner, C., Glade, T., 2015. Spatiotemporal patterns of landslide exposure -a step within future landslide risk analysis on a regional scale applied in Waidhofen/Ybbs Austria. Int. J. Disaster Risk Reduct. 12, 25-33. https://doi.org/10.1016/j.ijdrr.2014.11.003.

Prudhomme, C., Genevier, M., 2011. Can atmospheric circulation be linked to flooding in Europe? Hydrol. Process 25, 1180-1190. https://doi.org/10.1002/hyp.7879.

Ralph, F.M., Dettinger, M.D., 2012. Historical and national perspectives on extreme west coast precipitation associated with atmospheric rivers during december 2010. Bull. Am. Meteorol. Soc. 93, 783-790. https://doi.org/10.1175/BAMS-D-11-00188.1.

Ralph, F.M., Neiman, P.J., Wick, G.A., 2004. Satellite and CALJET aircraft observations of atmospheric rivers over the Eastern North Pacific Ocean during the winter of 1997/98. Mon. Weather Rev. 132, 1721-1745. https://doi.org/10.1175/1520-0493, (2004) $132<1721$ :SACAOO > 2.0.CO;2.

Ralph, F.M., Neiman, P.J., Wick, G.A., Gutman, S.I., Dettinger, M.D., Cayan, D.R., White, A.B., 2006. Flooding on California's Russian River: Role of atmospheric rivers. Geophys. Res. Lett. 33, 3-7. https://doi.org/10.1029/2006GL026689.

Ramos, A.M., Cortesi, N., Trigo, R.M., 2014a. Circulation weather types and spatial variability of daily precipitation in the Iberian peninsula. Front. Earth Sci. 2, 1-17. https://doi.org/10.3389/feart.2014.00025.

Ramos, A.M., Trigo, R.M., Liberato, M.L.R., 2017. Ranking of multi-day extreme precipitation events over the Iberian Peninsula. Int. J. Climatol. 37, 607-620. https://doi.org/10.1002/joc. 4726 .

Ramos, A.M., Trigo, R.M., Liberato, M.L.R., 2014b. A ranking of high-resolution daily precipitation extreme events for the Iberian Peninsula. Atmos. Sci. Lett. n/a-n/a 15, 328-334. https://doi.org/10.1002/asl2.507.

Ramos, A.M., Trigo, R.M., Liberato, M.L.R., Tomé, R., 2015. Daily precipitation extreme events in the Iberian peninsula and its association with atmospheric rivers. J. Hydrometeorol. 16, 579-597. https://doi.org/10.1175/JHM-D-14-0103.1.

Rebelo, L., Ramos, A., Pereira, S., Trigo, R., 2018. Meteorological driving mechanisms and human impacts of the February 1979 extreme hydro-geomorphological event in Western Iberia. Water 10, 454. https://doi.org/10.3390/w10040454.

Santos, P.P.Dos, Tavares, A.O., Zêzere, J.L., 2014. Risk analysis for local management from hydro-geomorphologic disaster databases. Environ. Sci. Policy 40, 85-100. https://doi.org/10.1016/j.envsci.2013.12.007.

Santos, M., Santos, J.A., Fragoso, M., 2017. Atmospheric driving mechanisms of flash floods in Portugal. Int. J. Climatol. 37, 671-680. https://doi.org/10.1002/joc.5030.

Santos, P.P., Pereira, S., Zêzere, J.L., Reis, E., Garcia, R.A.C., 2018. Flood susceptibility assessment based on analytical hierarchy process: Application in mainland Portugal. Geophys. Res. Abstr. 20, 85827.

Stohl, A., Forster, C., Sodemann, H., 2008. Remote sources of water vapor forming precipitation on the Norwegian west coast at $60^{\circ} \mathrm{N}$ - A tale of hurricanes and an atmospheric river. J. Geophys. Res. Atmos. 113, 1-13. https://doi.org/10.1029/2007JD009006.

Sun, Q., Miao, C., Duan, Q., Ashouri, H., Sorooshian, S., Hsu, K.L., 2018. A review of global precipitation data sets: Data sources, estimation, and intercomparisons. Rev. Geophys. 56, 79-107. https://doi.org/10.1002/2017RG000574.

Tavares, A.O., Pato, R.L., Magalhães, M.C., 2012. Spatial and temporal land use change and occupation over the last half century in a peri-urban area. Appl. Geogr. 34, 432444. https://doi.org/10.1016/j.apgeog.2012.01.009.

Trigo, R.M., DaCamara, C.C., 2000. Circulation weather types and their influence on the precipitation regime in Portugal. Int. J. Climatol. 20, 15591581. https://doi.org/10.1002/1097-0088, (20001115)20:13<1559::AIDJOC555 > 3.0.CO;2-5

Trigo, R.M., Ramos, C., Pereira, S.S., Ramos, A.M., Zêzere, J.L., Liberato, M.L.R., 2016. The deadliest storm of the 20th century striking Portugal: Flood impacts and atmospheric circulation. J. Hydrol. 541, 597-610. https://doi.org/10.1016/j.jhydrol.2015.10.036.

Trigo, R.M., Varino, F., Ramos, A.M., Valente, M., Zêzere, J.L., Vaquero, J.M., Gouveia, C.M., Russo, A., 2014. The record precipitation and flood event in Iberia in December 1876: Description and synoptic analysis. Front. Earth Sci. 2, 1-15. https://doi.org/10.3389/feart.2014.00003.

Trigo, R.M., Zêzere, J.L., Rodrigues, M.L., Trigo, I.F., 2005. The influence of the North Atlantic oscillation on rainfall triggering of landslides near Lisbon. Nat. Hazards 36, 331-354. https://doi.org/10.1007/s11069-005-1709-0.

Tschoegl, L., Below, R., Guha-Sapir, D., 2006. An analytical review of selected data sets on natural disasters and impacts. In: Proceedings of the UNDP/CRED Workshop on Improving Compilation of Reliable Data on Disaster Occurence and Impact. Bangkok.

Valenzuela, P., Iglesias, M., Domínguez-Cuesta, M., Mora García, M., 2018. Meteorological patterns linked to landslide triggering in Asturias (NW Spain): A preliminary analysis. Geosciences 8, 18. https://doi.org/10.3390/geosciences8010018.

Valenzuela, P., Iglesias, M., Domínguez-cuesta, M.J., Antonio, M., García, M., 2017. Meteorological conditions for the triggering of landslides in Asturias (NW Spain). A preliminary analysis of synoptic patterns.. Geophys. Res. Abstracts 69441. 
Vaz, T., Zezere, J.L., Pereira, S., Oliveira, S.C., Garcia, R.A.C., Quaresma, I., 2018. Regional rainfall thresholds for landslide occurrence using a centenary database. Nat. Hazards Earth Syst. Sci. 18, 1037-1054. https://doi.org/10.5194/nhess-18-1037-2018.

Ward, J.., 1963. Hierarchical grouping to optimize an objective function. J. Am. Stat. Assoc. 58, 236-244.

Zêzere, J.L., Oliveira, S.C., Pereira, S., Garcia, R.A.C., Melo, R., Vaz, T., Tavares, A.O., Bateira, C., Santos, P.P., Meneses, B., 2018. Construction of a national landslide susceptibility map for Portugal. Geophys. Res. Abstr. 20, 85827.

Zêzere, J.L., Pereira, S., Tavares, A.O., Bateira, C., Trigo, R.M., Quaresma, I., Santos, P.P., Santos, M., Verde, J., 2014. DISASTER: a GIS database on hydro-geomorphologic disasters in Portugal. Nat. Hazards 72, 503-532. https://doi.org/10.1007/s11069-013-1018-y.
Zêzere, J.L., Trigo, R.M., Trigo, I.F., 2005. Shallow and deep landslides induced by rainfall in the Lisbon region (Portugal): Assessment of relationships with the North Atlantic Oscillation. Nat. Hazards Earth Syst. Sci. 5, 331-344.

Zêzere, J.L., Vaz, T., Pereira, S., Oliveira, S.C., Marques, R., Garcia, R.A.C., 2015. Rainfall thresholds for landslide activity in Portugal: A state of the art. Environ. Earth Sci. 73, 2917-2936. https://doi.org/10.1007/s12665-014-3672-0.

Zhu, Y., Newell, R.E., 1998. A proposed algorithm for moisture fluxes from atmospheric rivers. Mon. Weather Rev. 126, 725-735. https://doi.org/10.1175/1520-0493, (1998) $126<0725$ :APAFMF $>2.0$. CO;2. 